\title{
Interaction of Halogenated Tyrosine/Phenylalanine Derivatives with Organic Anion Transporter 1 in the Renal Handling of Tumor Imaging Probes ${ }^{\text {[ }}$
}

\author{
Chunhuan Jin, Ling Wei, Ryuichi Ohgaki, Hideyuki Tominaga, Minhui Xu, Suguru Okuda, \\ Hiroki Okanishi, Yasuharu Kawamoto, ${ }^{1}$ Xin He, Shushi Nagamori, and Yoshikatsu Kanai \\ Department of Bio-system Pharmacology, Graduate School of Medicine (C.J., L.W., R.O., M.X., S.O., H.O., Ya.K., Yo.K.) and \\ Integrated Frontier Research for Medical Science Division, Institute for Open and Transdisciplinary Research Initiative (OTRI) \\ (Yo.K.), Osaka University, Osaka, Japan; Department of Oncology Clinical Development, Gunma University Graduate School of \\ Medicine, Maebashi, Gunma, Japan (H.T.); School of Traditional Chinese Medicine, Guangdong Pharmaceutical University, \\ Guangzhou, Guangdong, China (L.W., X.H.); and Department of Collaborative Research for Bio-Molecular Dynamics, Nara \\ Medical University, Nara, Japan (S.N.)
}

Received July 21, 2020; accepted September 16, 2020

\begin{abstract}
Halogenated tyrosine/phenylalanine derivatives have been developed for use in tumor imaging and targeted alpha therapy. 3-Fluoro- $\alpha$-methyl-L-tyrosine (FAMT), targeting amino acid transporter LAT1 (SLC7A5), is a cancer-specific positron emission tomography probe that exhibits high renal accumulation, which is supposed to be mediated by organic anion transporter OAT1 (SLC22A6). In the present study, we investigated the structural requirements of FAMT essential for interaction with OAT1. OAT1 transported FAMT with a $K_{\mathrm{m}}$ of $171.9 \mu \mathrm{M}$. In structure-activity relationship analyses, removal of either the 3-halogen or 4-hydroxyl group from FAMT or its structural analog 3-iodo$\alpha$-methyl-L-tyrosine greatly decreased the interaction with OAT1, reducing the $\left[{ }^{14} \mathrm{C}\right] p$-aminohippurate uptake inhibition and the efflux induction. By contrast, the $\alpha$-methyl group, which is essential for LAT1 specificity, contributed to a lesser degree. In fluorinated tyrosine derivatives, fluorine at any position was accepted by OAT1 when there was a hydroxyl group at the ortho-position, whereas ortho-fluorine was less interactive when a hydroxyl group was at meta- or parapositions. The replacement of the ortho-fluorine with a bulky iodine atom greatly increased the interaction. In in vivo
\end{abstract}

studies, probenecid decreased the renal accumulation $(P<$ $0.001)$ and urinary excretion $(P=0.0012)$ of FAMT, whereas the plasma concentration was increased, suggesting the involvement of OAT1-mediated transepithelial organic anion excretion. LAT1-specific 2-fluoro- $\alpha$-methyltyrosine, which had lower affinity for OAT1, exhibited lower renal accumulation $(P=0.0142)$ and higher tumor uptake $(P=0.0192)$ compared with FAMT. These results would provide a basis to design tumor-specific compounds that can avoid renal accumulation for tumor imaging and targeted alpha therapy.

\section{SIGNIFICANCE STATEMENT}

We revealed the structural characteristics of halogenated tyrosine derivatives essential for interaction with the organic anion transporter responsible for their renal accumulation. We have confirmed that such interactions are important for renal handling and tumor uptake. The critical contribution of hydroxyl and halogen groups and their positions as well as the role of $\alpha$-methyl group found in the present study may facilitate the development of tumor-specific compounds while avoiding renal accumulation for use in tumor imaging and targeted alpha therapy.

\section{Introduction}

Halogenated aromatic amino acid derivatives have been developed for potential use as tracers in positron emission

This work was supported by Grants-in-Aid for Scientific Research from the Japan Society for the Promotion of Science [19H03407] (to Y.K.) and the Project for Development of Innovative Research on Cancer Therapeutics from Japan Agency for Medical Research and Development [17cm0106118], [JP18cm0106131], [JP19cm0106151], and [JP20cm0106151] (to Y.K.).

${ }^{1}$ Current affiliation: Osaka Police Hospital, Osaka, Japan.

This work was previously presented in part as follows: C.J. et al, L-type amino acid transporter 1 (LAT1) in endothelial cells of tumor vessels contributes to tumor angiogenesis, The $18^{\text {th }}$ World Congress of Basic and Clinical Pharmacology, July 2, 2018, Kyoto, Japan. C.J. et al, Critical moieties of aromatic amino acid probes causing renal accumulation in tumor imaging, The $92^{\text {nd }}$ Annual Meeting for the Japanese Pharmacological Society, March 14, 2019, Osaka, Japan.

https://doi.org/10.1124/jpet.120.000235.

S This article has supplemental material available at jpet.aspetjournals.org. tomography (PET) and single-photon emission computed tomography (SPECT) for the clinical diagnosis of malignant tumors (Jager et al., 2001; Plathow and Weber, 2008). Amino acid probes are advantageous in cancer diagnosis because of their cancer specificity, which could overcome the issues of false positives and high physiologic backgrounds in conventionally used 2-[ $\left.{ }^{18} \mathrm{~F}\right]$ fluoro-2-deoxy-D-glucose-PET imaging (Cook et al., 1999). We have previously reported that the halogenated tyrosine derivatives, 3-fluoro- $\alpha$-methyl-L-tyrosine (FAMT) and 3-iodo- $\alpha$-methyl-L-tyrosine (IMT), used as cancer-specific probes for PET and SPECT, respectively, are highly specific to LAT1 (SLC7A5) among amino acid transporters (Wiriyasermkul et al., 2012; Wei et al., 2016b). LAT1 is an amino acid transporter predominantly expressed in primary tumors of various tissue origins and their metastatic lesions (Kandasamy et al., 2018). LAT1 primarily transports branched-chain and aromatic amino 
acids and their derivatives (Kanai et al., 1998; Uchino et al., 2002). The LAT1 specificity of FAMT and IMT is due to their $\alpha$-methyl groups (Wiriyasermkul et al., 2012).

In $\left[{ }^{18} \mathrm{~F}\right]$ FAMT-PET and $\left[{ }^{123} \mathrm{I}\right] \mathrm{IMT}$-SPECT imaging, the kidney is the only organ that demonstrates high physiologic uptake, which limits the use of these compounds for imaging of abdominal tumors (Shikano et al., 2004b; Suzuki et al., 2014). Based on the effects of organic anion transporter inhibitors, such as probenecid, it has been proposed that the renal accumulation of IMT is mediated by the accumulative transepithelial organic anion excretion pathway in the S2 segment of renal proximal tubules (Shikano et al., 2004b; Nakajima et al., 2007). Because FAMT and IMT are structurally identical, except for the fluorine/iodine substitution at position 3 of the benzene ring, we hypothesized that the renal handling of FAMT could be similar to that of IMT and sought to determine which renal transporters transport FAMT. Among organic ion transporters involved in the uptake into tubular epithelial cells, we reported that the transporters OAT1 (SLC22A6) in the basolateral membrane and OAT10 (SLC22A13) and OCTN2 (SLC22A5) in the apical membrane could transport FAMT (Wei et al., 2016a). Among them, OAT1 is a transporter involved in the accumulative transepithelial organic anion excretion pathway (Anzai et al., 2006).

In the present study, we examined the interaction of FAMT and its related compounds with OAT1 to reveal the structural characteristics of FAMT essential for interaction with OAT1 and finally identified the halogenated compounds with low affinity for OAT1 yet high specificity for LAT1. We furthermore conducted in vivo studies to evaluate the relevance of OAT1 in the renal handling of FAMT and its related compounds, as well as their tumor accumulation. The structure-activity relationship analysis in the present study was designed based on reports showing that 4-iodo-L-metatyrosine (4-I- $m$-Tyr), which has differences in halogen, hydroxyl, and $\alpha$-methyl groups compared with IMT/FAMT (Fig. 1), targeted LAT1 similar to IMT/FAMT, yet it exhibited decreased renal accumulation (Shikano et al., 2003). Using a series of halogenated tyrosine/phenylalanine derivatives, we report that the presence and/or relative positions of halogen, hydroxyl, and $\alpha$-methyl groups are critical for interaction with OAT1. The results of the present study provide a basis to design tumor-specific compounds that avoid renal accumulation for tumor imaging. Such compounds would also be beneficial for efficient targeted alpha therapy targeting LAT1 while avoiding renal damage (Watabe et al., 2020).

\section{Materials and Methods}

Materials. FAMT and 2-fluoro-L- $\alpha$-methyltyrosine (2-FAMT) were obtained from Nard Institute, Ltd. (Amagasaki, Japan) (Wiriyasermkul et al., 2012). $\left[{ }^{14} \mathrm{C}\right]$ FAMT $(1.77 \mathrm{GBq} / \mathrm{mmol})$ was obtained from Sekisui Medical (Tokyo, Japan) (Wei et al., 2016a). $\left[{ }^{14} \mathrm{C}\right] p$-aminohippurate acid (PAH) $(1.931 \mathrm{GBq} / \mathrm{mmol})$ was purchased from Moravek Biochemicals (Brea, CA). Standard amino acids and L- $\alpha$-methyltyrosine (AMT) were purchased from Sigma-Aldrich (St Louis, MO). IMT was obtained from Advance Bio-chemical Compounds GmbH (Radeberg, Germany). 3Fluoro-L-tyrosine (3-FT) was purchased from Tokyo Chemical Industry (Tokyo, Japan). Unless specially denoted, other chemicals and cell media were purchased from Wako Pure Chemical Industries (Osaka, Japan). The chemical structures of compounds used in the present study are presented in Fig. 1.

Establishment of a Stable OAT1-Expressing Cell Line. A stable cell line of doxycycline-inducible expression of human OAT1 was constructed. The coding sequence of human OAT1 (GenBank Accession: AB009697.1) was amplified by polymerase chain reaction from pcDNA3.1(+)-hOAT1 (Ichida et al., 2003) using the primer pair 5'-CGGGATCCATGGCCTTTAATGACCTCCTG-3' (forward) and 5'CTCCTCGAGTCAGAGTCCATTCTTCTCTTG-3' (reverse). The amplified fragment was digested by BamHI and XhoI and ligated into the pcDNA5/FRT/TO vector (Invitrogen, Carlsbad, CA) at BamHI and XhoI sites to obtain pcDNA5/FRT/TO-hOAT1.

Flp-In T-REx 293 cells (Nagamori et al., 2016) were cultured in Dulbecco's modified Eagle's medium (Wako Pure Chemical Industries) supplemented with 10\% FBS (Gibco, Grand Island, NY) and 1\% (v/v) penicillin-streptomycin solution (Nakalai Tesque, Kyoto, Japan). FlpIn T-REx 293 cells were transfected and screened with pcDNA5/FRT/ TO-hOAT1 as described previously (Nagamori et al., 2016) with a minor modification. Two days after transfection, the cells were passaged. After cells attached, the growth medium was replaced with selection media containing $100 \mu \mathrm{g} / \mathrm{ml}$ hygromycin B (Nacalai Tesque) and $5 \mu \mathrm{g} / \mathrm{ml}$ blasticidin (Invitrogen). The selection medium was changed every 3 to 4 days until the desired number of cells was grown. The cell colonies were examined by reverse transcription-polymerase chain reaction for the expression of human OAT1. A positive cell line, designated FlpIn293TetR-hOAT1, was functionally confirmed by the uptake of $\left[{ }^{14} \mathrm{C}\right] \mathrm{PAH}$ (see below) and used for the present study.

Cell Culture. FlpIn293-TetR-OAT1 cells with inducible human OAT1 expression (Tet-On) were cultured in Dulbecco's modified Eagle's medium supplemented with FBS (10\%), penicillin-streptomycin (1\%), hygromycin B $(100 \mu \mathrm{g} / \mathrm{ml})$, and blasticidin $(5 \mu \mathrm{g} / \mathrm{ml})$ in a humidified incubator at $37^{\circ} \mathrm{C}$ supplied with $5 \% \mathrm{CO}_{2}$. At 48 hours before uptake/ efflux experiments, cells were seeded on poly-D-lysine-coated 24 -well plates at a density of $1.5 \times 10^{5}$ cells per well, with or without $1 \mu \mathrm{g} / \mathrm{ml}$ doxycycline (Dox).

Uptake Measurements and Inhibition Experiments. Uptake measurements were conducted as described previously (Ohgaki et al., 2016). The uptake of $\left[{ }^{14} \mathrm{C}\right] \mathrm{PAH}$ and $\left[{ }^{14} \mathrm{C}\right] \mathrm{FAMT}$ by cells was measured for 1 minute or indicated time periods in $\mathrm{Na}^{+}$-free Hanks' balanced salt solution (HBSS: $125 \mathrm{mM}$ choline chloride, $4.8 \mathrm{mM} \mathrm{KCl,} 1.2 \mathrm{mM}$ $\mathrm{MgSO}_{4}, 1.2 \mathrm{mM} \mathrm{KH} \mathrm{PO}_{4}, 1.3 \mathrm{mM} \mathrm{CaCl} 2,5.6 \mathrm{mM}$ D-glucose, and $25 \mathrm{mM}$ 4-morpholineethanesulfonic acid, $\mathrm{pH}$ 7.4). After uptake was terminated, the cells were lysed, and the radioactivity was measured using a $\beta$-scintillation counter (LSC-3100; Aloka, Tokyo, Japan). The protein concentrations of cell lysates were determined using a Micro BCA Protein Assay Kit (Thermo Fisher Scientific, Rockford, IL). OAT1-mediated uptake was calculated by subtracting the uptake value without Dox treatment from that with Dox treatment. To determine kinetic parameters, OAT1-mediated $\left[{ }^{14} \mathrm{C}\right]$ FAMT uptake was plotted against FAMT concentration and fitted to a MichaelisMenten curve. The Michaelis constant $\left(K_{\mathrm{m}}\right)$, the maximal uptake rate $\left(V_{\max }\right)$, and Eadie-Hofstee plot were obtained using the enzyme kinetics module of GraphPad Prism 7 (GraphPad Software Inc., San Jose, CA). Kinetic data are summarized in Table 1.

\footnotetext{
ABBREVIATIONS: AMT, L- $\alpha$-methyltyrosine; $\mathrm{AUC}_{0-\infty}$, area under the plasma concentration-time curve from zero to infinity; $\mathrm{CL}_{\text {renal }}$, renal clearance; Dox, doxycycline; 3-F-AMP, (S)- $\alpha$-methyl-3-fluorophenylalanine; FAMT, 3-fluoro- $\alpha$-methyl-L-tyrosine; 2-FAMT, 2-fluoro- $\alpha$-methylL-tyrosine; F- $m$-Tyr, fluoro-meta-tyrosine; F-o-Tyr, fluoro-ortho-tyrosine; 2-FT, 2-fluorotyrosine; 3-FT, 3-fluorotyrosine; $f_{\mathrm{u}}$, free compound fraction; HBSS, Hanks' balanced salt solution; HPLC, high performance liquid chromatography; 3-I-AMP, (S)- $\alpha$-methyl-3-iodophenylalanine; IMT, 3-iodo$\alpha$-methyl-L-tyrosine; 4-I- $m$-Tyr, 4-iodo-L-meta-tyrosine; 2-IT, 2-iodo-L-tyrosine; 3-IT, 3-iodo-L-tyrosine; LAT, L-type amino acid transporter; OAT, organic anion transporter; OCT, organic cation transporter; PAH, $p$-aminohippuric acid; PET, positron emission tomography; SLC, solute carrier; SPECT, single-photon emission computed tomography.
} 
A<smiles>CC(N)(Cc1ccc(O)c(I)c1)C(=O)O</smiles>

3-iodo-L-a-methyl-tyrosine (IMT)<smiles>CC(N)(Cc1ccc(O)c(F)c1)C(=O)O</smiles>

3-fluoro-L-a-methyl-tyrosine (FAMT)

B<smiles>NC(Cc1ccc(O)c(I)c1)C(=O)O</smiles>

3-iodo-L-tyrosine (3-IT)

C

Group I.<smiles>NC(Cc1ccc(O)c(F)c1)C(=O)O</smiles>

\section{3-fluoro-tyrosine} (3-FT)

Group II.<smiles>NC(Cc1ccc(F)c(O)c1)C(=O)O</smiles>

\section{4-fluoro-meta-tyrosine} (4-F-m-Tyr)

Group III.<smiles>NC(Cc1cccc(F)c1O)C(=O)O</smiles>

3-fluoro-ortho-tyrosine (3-F-o-Tyr)<smiles>CC(N)(Cc1cccc(I)c1)C(=O)O</smiles>

(S)-a-methyl-3-iodophenylalanine (3-I-AMP)<smiles>CC(N)(Cc1cccc(F)c1)C(=O)O</smiles>

(S)-a-methyl-3-fluorophenylalanine (3-F-AMP)<smiles>NC(Cc1ccc(O)cc1I)C(=O)O</smiles>

2-iodo-L-tyrosine (2-IT)<smiles>NC(Cc1ccc(O)cc1F)C(=O)O</smiles>

\section{2-fluoro-tyrosine} (2-FT)<smiles>CC(N)(Cc1ccc(O)cc1)C(=O)O</smiles>

\section{L-a-methyl-tyrosine} (AMT)<smiles>CC(N)(Cc1ccc(O)cc1F)C(=O)O</smiles>

2-fluoro-L-a-methyl-tyrosine (2-FAMT)<smiles>NC(Cc1ccc(I)c(O)c1)C(=O)O</smiles>

4-iodo-L-meta-tyrosine (4-I-m-Tyr)

Fig. 1. Chemical structures of compounds used in this study. (A) $\alpha$-Methyl aromatic amino acids. (B) Iodinated aromatic amino acids. (C) Fluorinated aromatic amino acids. Groups I, II, and III represent compounds with a hydroxyl group at the para-, meta-, and ortho-positions of the benzene ring, respectively.

For inhibition experiments, OAT1-mediated uptake of $\left[{ }^{14} \mathrm{C}\right] \mathrm{PAH}$ $(1 \mu \mathrm{M})$, a typical substrate of OAT1, was measured for 1 minute with or without nonradiolabeled test compounds at the indicated concentrations. The $\mathrm{IC}_{50}$ of each compound was determined by experiments in which OAT1-mediated uptake of $\left[{ }^{14} \mathrm{C}\right] \mathrm{PAH}(1 \mu \mathrm{M})$ was measured for 1 minute in the presence of the compound at concentrations of $1,3,10,30,100,300,1000$, and $3000 \mu \mathrm{M} . \mathrm{IC}_{50}$ values were obtained by fitting the data to inhibition curves using nonlinear regression analysis in GraphPad Prism 7 (GraphPad
Software Inc.). $\mathrm{IC}_{50}$ values obtained by inhibition experiments are summarized in Table 1.

Efflux Measurements. Efflux measurements were conducted as described previously (Shiraya et al., 2010; Wiriyasermkul et al., 2012). The cells were preloaded with $\left[{ }^{14} \mathrm{C}\right] \mathrm{PAH}$ for 10 minutes in $\mathrm{Na}^{+}$-free HBSS containing $100 \mu \mathrm{M}\left[{ }^{14} \mathrm{C}\right] \mathrm{PAH}(1.931 \mathrm{MBq} / \mathrm{mmol})$ via OAT1mediated uptake. After washing the cells with $\mathrm{Na}^{+}$-free HBSS three times, the efflux was initiated by changing the medium to $\mathrm{Na}^{+}$-free HBSS with or without the indicated concentrations of nonradiolabeled 
TABLE 1

Kinetic parameters of each compound on OAT1

\begin{tabular}{|c|c|c|c|}
\hline Compound & $\mathrm{IC}_{50}(\mu \mathrm{M})^{a}$ & $K_{\mathrm{m}}$ of Efflux $(\mu \mathrm{M})^{a}$ & Estimated $\mathrm{p} K_{\mathrm{a}}$ of Hydroxyl Group ${ }^{b}$ \\
\hline FAMT $^{c}$ & $453.1 \pm 14.3^{d}$ & $690.8 \pm 18.9^{d}$ & 8.4 \\
\hline IMT & $118.5 \pm 12.7$ & $146.8 \pm 11.3$ & 8.4 \\
\hline $4-\mathrm{I}-m$-Tyr & $737.5 \pm 12.1$ & $452.7 \pm 10.1$ & 8.3 \\
\hline 3 -IT & $236.2 \pm 12.7$ & $73.8 \pm 6.8$ & 8.3 \\
\hline 3-FT & $757.1 \pm 16.4$ & $339.4 \pm 13.4$ & 8.4 \\
\hline 3-I-AMP & N.D. $e^{e}$ & & \\
\hline 3-F-AMP & N.D. & & \\
\hline AMT & N.D. & & 9.3 \\
\hline 2-FAMT & N.D. & & 8.5 \\
\hline 2-IT & $82.3 \pm 15.6$ & $64.0 \pm 6.4$ & 8.8 \\
\hline 2-FT & N.D. & $1166 \pm 18.3$ & 8.8 \\
\hline 2 -F-m-Tyr & $749.4 \pm 24.6$ & & 8.3 \\
\hline $4-\mathrm{F}-m-\mathrm{Tyr}$ & $534.6 \pm 10.3$ & $419.4 \pm 19.7$ & 8.3 \\
\hline $5-\mathrm{F}-m$-Tyr & $371.5 \pm 7.2$ & & 8.4 \\
\hline $6-\mathrm{F}-m$-Tyr & N.D. & & 8.9 \\
\hline 3-F-o-Tyr & $401.3 \pm 9.1$ & & 8.2 \\
\hline 4-F-o-Tyr & $607.8 \pm 11.4$ & & 8.3 \\
\hline 5-F-o-Tyr & $852.5 \pm 13.4$ & & 8.7 \\
\hline $6-\mathrm{F}-o-\mathrm{Tyr}$ & $756.5 \pm 19.6$ & & 8.3 \\
\hline
\end{tabular}

${ }^{a} \mathrm{IC}_{50}$ of the compound to inhibit OAT1-mediated $\left[{ }^{14} \mathrm{C}\right] \mathrm{PAH}(1 \mu \mathrm{M})$ uptake and the $K_{\mathrm{m}}$ to induce OAT1-mediated $\left[{ }^{14} \mathrm{C}\right] \mathrm{PAH}$ efflux were determined in OAT1 cells as described in Materials and Methods.

${ }^{b}$ The $\mathrm{p} K_{\mathrm{a}}$ value of hydroxyl group on the benzene ring was estimated by the Calculator Plugins, MarvinSketch version 20.14 .0 (ChemAxon).

${ }^{c}$ Kinetic parameters of OAT1-mediated $\left[{ }^{14} \mathrm{C}\right]$ FAMT uptake were further determined: $K_{\mathrm{m}}, 171.9 \pm 16.6 \mu \mathrm{M} ; V_{\mathrm{max}}, 3391 \pm 27.3 \mathrm{pmol} / \mathrm{mg}$ per minute.

${ }^{d}$ Values represent mean \pm S.D. $(n=4)$.

${ }^{e}$ N.D. indicates "not determined."

test compounds and measured for 1 minute. The medium was then collected, and the radioactivity in the medium and the remaining radioactivity in the cells were counted. $\left[{ }^{14} \mathrm{C}\right] \mathrm{PAH}$ efflux was expressed as a percentage of total radioactivity (the radioactivity of the medium divided by the sum of the radioactivity of the medium and the remaining radioactivity in cells). The $\left[{ }^{14} \mathrm{C}\right] \mathrm{PAH}$ efflux induced by test compounds was calculated by subtracting the $\left[{ }^{14} \mathrm{C}\right] \mathrm{PAH}$ efflux in the absence of the test compounds from that in the presence of test compounds.

The kinetic parameters of test compounds in the induction of $\left[{ }^{14} \mathrm{C}\right]$ PAH efflux were determined at the concentrations of 1, 3, 10, 30, 100, 300 , and $1000 \mu \mathrm{M}$. The $\left[{ }^{14} \mathrm{C}\right] \mathrm{PAH}$ efflux induced by test compounds was plotted against the concentration of the compounds and fitted to a Michaelis-Menten curve. $K_{\mathrm{m}}$ and $V_{\max }$ were determined using an Eadie-Hofstee plot. The $K_{\mathrm{m}}$ values obtained are summarized in Table 1.

Tissue Accumulation and Urinary Excretion Studies. Animal experiments were conducted with approval according to the regulations of the Animal Care and Use Committee of Osaka University.

To examine the effects of probenecid on renal accumulation, plasma concentration, and urinary excretion of FAMT, male ddY mice (4-6 weeks, $20-25 \mathrm{~g})$ were intravenously administered FAMT $(1.5 \mathrm{mg} / \mathrm{kg})$ in $0.1 \mathrm{ml}$ saline $(0.9 \% \mathrm{NaCl})$ from the tail vein. Probenecid $(50 \mathrm{mg} / \mathrm{kg})$ in $0.1 \mathrm{ml}$ saline was preadministered through the tail vein 10 minutes before the injection of FAMT. At 10 minutes after the administration of FAMT, mice were anesthetized by intraperitoneal injection of three types of mixed anesthetic agents $(0.3 \mathrm{mg} / \mathrm{kg}$ of medetomidine, $4.0 \mathrm{mg} / \mathrm{kg}$ of midazolam, and $5.0 \mathrm{mg} / \mathrm{kg}$ of butorphanol in saline), and fresh urine was collected by puncture of the bladder. The animals were euthanized under deep anesthesia, and kidneys were dissected out and weighed. After rinsing in PBS, the kidneys were stored at $-80^{\circ} \mathrm{C}$ for high performance liquid chromatography (HPLC) analysis. Blood was taken at the same time by cardiac puncture into tubes containing sodium citrate solution $(3.2 \%, 25 \mu \mathrm{l})$. Blood samples were centrifuged at $2000 \mathrm{~g}$ at $4^{\circ} \mathrm{C}$ for 15 minutes. The obtained plasma was adjusted to $1 \mathrm{ml}$ with deionized water and stored at $-80^{\circ} \mathrm{C}$.

For the comparison of the renal accumulation, plasma concentration, and urinary excretion of FAMT, 2-FAMT, and 2-FT, male ddY mice (4-6 weeks, 25-30 g) were administered equimolar amounts of FAMT (1.5 mg/kg), 2-FAMT (1.5 mg/kg), or 2 -FT ( $1.4 \mathrm{mg} / \mathrm{kg})$ in $0.1 \mathrm{ml}$ saline $(0.9 \% \mathrm{NaCl})$ intravenously from the tail vein. At 10 minutes after administration, kidneys, blood, and urine were collected and processed as described above.

To compare the accumulation of FAMT and 2-FAMT in tumors, tumor-bearing mice were prepared by inoculating B16F10 mouse melanoma cells $\left(1 \times 10^{5}\right.$ cells per head $)$ into the back of male C57BL/6J mice ( 5 to 6 weeks, 18-22 g). When palpable tumors developed ( $\sim 10 \mathrm{~mm}$ in diameter $)$, mice were administrated FAMT $(1.5 \mathrm{mg} / \mathrm{kg})$ or 2 -FAMT $(1.5 \mathrm{mg} / \mathrm{kg})$ in $0.1 \mathrm{ml}$ saline $(0.9 \% \mathrm{NaCl})$ intravenously via the tail vein. At 10 minutes or 1 hour after injection, mice were anesthetized and sacrificed as described above. Tumors and the kidney and skeletal muscle were dissected.

Pharmacokinetic Studies in Mice. To determine pharmacokinetic parameters of FAMT and 2-FAMT, kidneys, blood, and urine were collected at different time points ( 10 minutes, 30 minutes, 1 hour, 2 hours, and 3 hours) after the intravenous administration of FAMT $(1.5 \mathrm{mg} / \mathrm{kg})$ or 2 -FAMT $(1.5 \mathrm{mg} / \mathrm{kg})$ in $\mathrm{ddY}$ mice and processed as described above. Pharmacokinetic parameters were calculated by means of the noncompartmental analysis (WinNonlin, version 8.1.0; Pharsight, Mountain View, CA). The area under the plasma concentration-time curve from zero to infinity $\left(\mathrm{AUC}_{0-\infty}\right)$ and the elimination rate constant $\left(K_{\mathrm{e}}\right)$ were calculated by a nonlinear leastsquares method. The renal clearance $\left(\mathrm{CL}_{\text {renal }}\right)$ was calculated by dividing the amount of compound excreted into urine by $\mathrm{AUC}_{0-\infty}$ (Imaoka et al., 2007)

Protein Binding Assays. Protein biding assays for FAMT and 2FAMT were conducted in terms of plasma protein binding and tumor tissue protein binding using the plasma and tumors obtained from B16F10 tumor-bearing C57BL/6J mice prepared as described above. Plasma protein binding assay was performed as described previously (Ohshima et al., 2013). A 20- $\mu$ l solution of FAMT or 2-FAMT $(50 \mathrm{nmol} /$ $\mathrm{ml}$ saline) was added to $180 \mu \mathrm{l}$ of freshly prepared plasma to make up the final concentration of $5 \mathrm{nmol} / \mathrm{ml}$, which was close to the plasma concentration as well as the concentration in tumor (the amount of the compound per gram of tumor tissue) at 1 hour after the intravenous administration. Then, the samples were incubated at $37^{\circ} \mathrm{C}$ for 1 hour and filtered through a $10-\mathrm{kDa}$ Amicon Ultra Centrifugal tube (Merck Millipore Ltd., Ireland). The amount of unbound FAMT and 2-FAMT was analyzed by HPLC as described below. The protein-unbound free compound fraction $\left(f_{\mathrm{u}}\right)$ was expressed as a percentage of free compound to the total amount in the sample. For tumor protein 
binding, tumors were homogenized by adding saline with the volume ratio of 1:4 (one volume of tumor with four volumes of saline) on ice. The homogenate was processed in the same manner as the plasma, described above, and $f_{\mathrm{u}}$ was obtained for FAMT and 2-FAMT.

HPLC Analysis. Urine and tissue samples were measured using HPLC. Urine samples were adjusted to a volume of $200 \mu l$ with PBS. Kidney samples were homogenized on ice using a Physcotron NS-310E II (Microtec, Chiba, Japan) in PBS, and the volume was adjusted to $1000 \mu \mathrm{l}$. After filtering with a syringe filter $(0.45 \mu \mathrm{m})$, the samples $(10 \mu \mathrm{l})$ were vigorously mixed with $190 \mu \mathrm{l}$ methanol for deproteinization and centrifuged at $15,000 \mathrm{~g}$ at $4^{\circ} \mathrm{C}$ for 30 minutes. The supernatant $(100 \mu \mathrm{l})$ was transferred and dried in a vacuum chamber. The sediment was reconstituted in $20 \mu \mathrm{l}$ of $200 \mu \mathrm{M}$ sodium borate $(\mathrm{pH}$ 8.0). For fluorescence derivatization, $5 \mu \mathrm{l}$ of $40 \mathrm{mM} 4$-fluoro-7-nitro2,1,3-benzoxadiazole in acetonitrile was added, and samples were heated at $60^{\circ} \mathrm{C}$ for 2 minutes, as described previously (Wongthai et al., 2015). Derivatization reactions were terminated by adding $75 \mu \mathrm{l}$ of $0.5 \%$ trifluoroacetic acid aqueous solution. Ten microliters of each sample was separated by a NANOSPACE SI-2 HPLC system (Shiseido, Tokyo, Japan) with a fluorescence detector. The analytical column was Capcell Pak $\mathrm{C}_{18}$ MGII S5 $(250 \times 2.0 \mathrm{~mm}$ i.d.). The mobile phase was acetonitrile/trifluoroacetic acid/water (27.5:0.05:72.5, v/v/v), with a flow rate of $200 \mu \mathrm{l} / \mathrm{min}$. Isocratic elution was conducted for 60 minutes. The compounds in samples were quantified by comparing the peak height with that of a standard of a known amount. The content of the compounds was expressed as a percentage of injected dose normalized per gram of tissue (wet weight).

Statistical Analysis. All experiments were conducted in four replicates. The data are expressed as means \pm S.D. Statistical differences were determined using the unpaired Student's $t$ test (two sets of data) or one-way ANOVA with Dunnett's post-test (more than two sets of data, multiple-to-one comparisons). One-way ANOVA with Tukey's honestly significant difference was used for comparisons of differences among groups. Differences were considered significant at $P<0.05$.

\section{Results}

Characterization of OAT1-Mediated Transport in the Stable Cell Line. To examine the interaction of FAMTrelated compounds with OAT1, we established a cell line, FlpIn293-TetR-hOAT1, expressing human OAT1 (hereafter referred to as "OAT1 cells"). OAT1 cells exhibited $\left[{ }^{14} \mathrm{C}\right] \mathrm{PAH}$ uptake dependent on Dox treatment, confirming the functional expression of human OAT1 (Supplemental Fig. 1A). The difference between the uptake with and without Dox treatment was calculated to be OAT1-mediated uptake. Because the $\left[{ }^{14} \mathrm{C}\right] \mathrm{PAH}$ uptake showed a linear dependence on the incubation time up to 5 minutes (Supplemental Fig. $1 B$ ), uptake was measured for 1 minute in all subsequent experiments.

To examine whether test compounds were transported by OAT1, we conducted efflux experiments by taking advantage of the obligatory exchanger property of OAT1. Because OAT1 mediates hetero- or homosubstrate exchange of its substrates (Sekine et al., 1997; Apiwattanakul et al., 1999), extracellular $\mathrm{PAH}$ induced the efflux of preloaded $\left[{ }^{14} \mathrm{C}\right] \mathrm{PAH}$ in OAT1 cells; $\left[{ }^{14} \mathrm{C}\right] \mathrm{PAH}$ released from cells was higher in the presence of extracellular PAH than that in its absence (Supplemental Fig. 1C). To confirm that $\left[{ }^{14} \mathrm{C}\right] \mathrm{PAH}$ efflux induced by extracellular OAT1 substrates was actually mediated by OAT1 in the established cell line, we preloaded equivalent amounts of $\left[{ }^{14} \mathrm{C}\right] \mathrm{PAH}$ into OAT1-expressing cells and nonexpressing cells and compared the efflux of $\left[{ }^{14} \mathrm{C}\right] \mathrm{PAH}$ induced by extracellular $\mathrm{PAH}$. Equivalent preloading of $\left[{ }^{14} \mathrm{C}\right] \mathrm{PAH}$ in OAT1-expressing

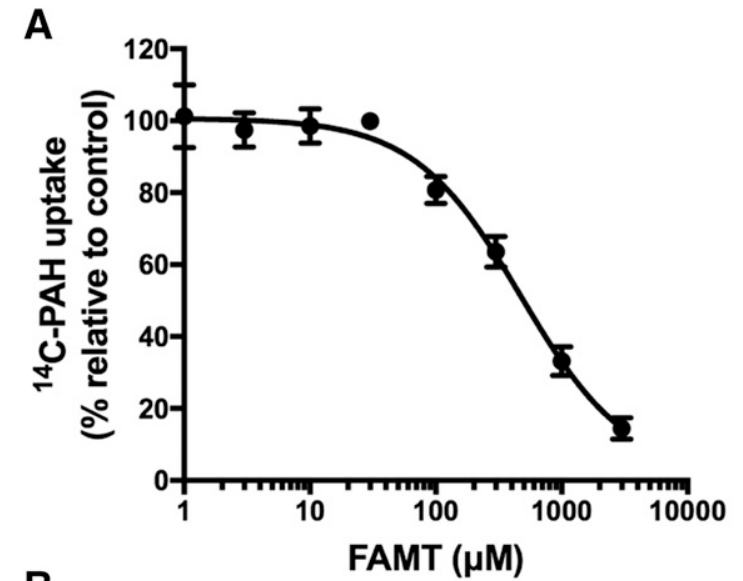

B

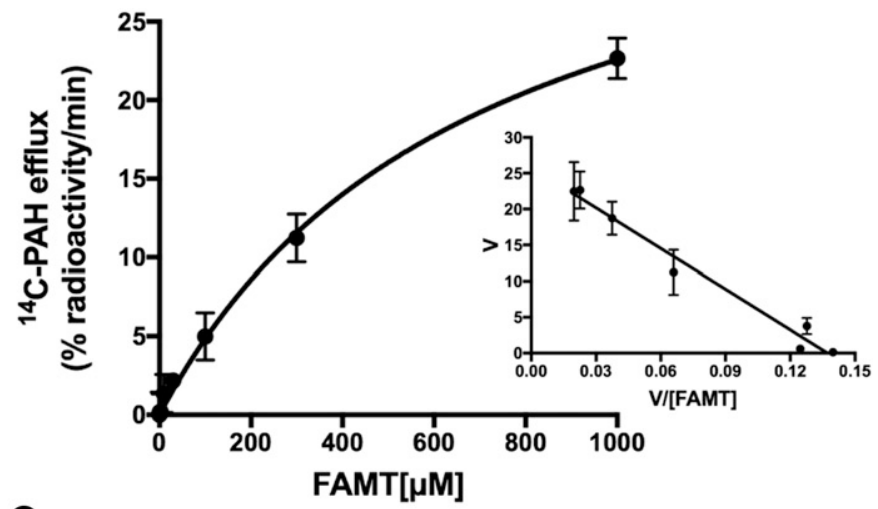

C

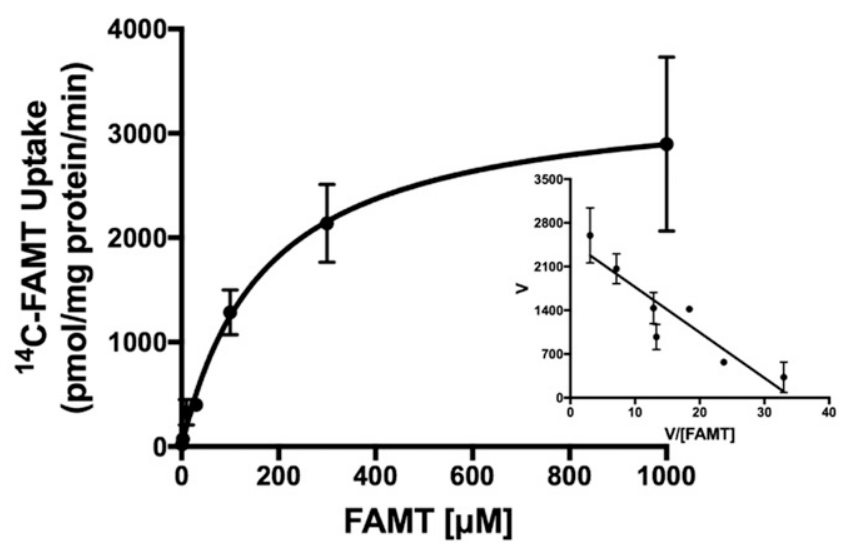

Fig. 2. Transport of FAMT by OAT1. (A) Concentration-dependent inhibition of $\left[{ }^{14} \mathrm{C}\right] \mathrm{PAH}$ uptake by FAMT in OAT1 cells. Uptake of $\left[{ }^{14} \mathrm{C}\right]$ PAH $(1 \mu \mathrm{M})$ was measured in the presence of various concentrations of FAMT. Uptake values were fitted to inhibition curves. IC $_{50}$ of FAMT on OAT1-mediated $\left[{ }^{14} \mathrm{C}\right] \mathrm{PAH}$ uptake was $453.1 \pm 14.3 \mu \mathrm{M}(n=4)$. (B) Concentration dependence of FAMT-induced $\left[{ }^{1 \overline{4}} \mathrm{C}\right] \mathrm{PAH}$ efflux in OAT1 cells. The efflux of preloaded $\left[{ }^{14} \mathrm{C}\right] \mathrm{PAH}$ from OAT1 cells was measured for 1 minute in the presence or absence of extracellular FAMT. The FAMTinduced efflux at each concentration of FAMT was obtained as described in Materials and Methods and plotted against the concentration of FAMT. The curve fit to Michaelis-Menten equation. The inset shows EadieHofstee plot [ordinate: V (\% radioactivity per minute); abscissa: V (\% radioactivity per minute)/[FAMT] (micromolar)], which was used to determine kinetic parameters. $K_{\mathrm{m}}$ of $690.8 \pm 18.9 \mu \mathrm{M}$ and $V_{\max }$ of $38.1 \% \pm$ $7.3 \%$ radioactivity/min were obtained $(n=4)$. (C) Concentration dependence of $\left[{ }^{14} \mathrm{C}\right] \mathrm{FAMT}$ uptake mediated by OAT1. OAT1-mediated uptake of $\left[{ }^{14} \mathrm{C}\right] \mathrm{FAMT}$ at each concentration was measured for 1 minute. Uptake rates were fit to Michaelis-Menten curve. Inset shows EadieHofstee plot [ordinate: V (picomole per milligram protein per minute]; abscissa: $\mathrm{V}$ [picomole per milligram protein per minute)/[FAMT] (micromolar)]. $K_{\mathrm{m}}$ of $171.9 \pm 16.6 \mu \mathrm{M}$ and $V_{\max }$ of $3391 \pm 27.3 \mathrm{pmol} / \mathrm{mg}$ per minute were obtained $(n=4)$. 
A

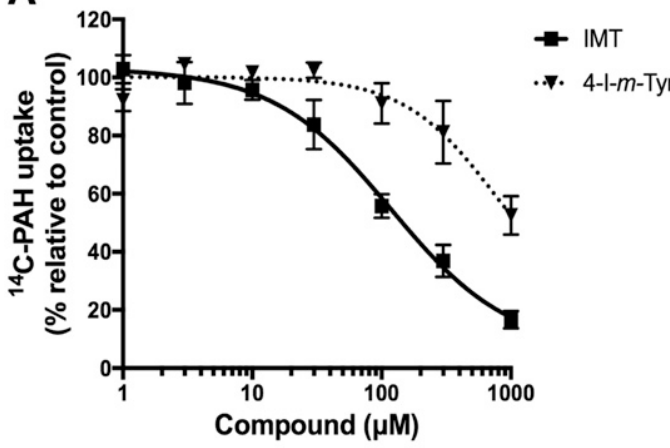

B

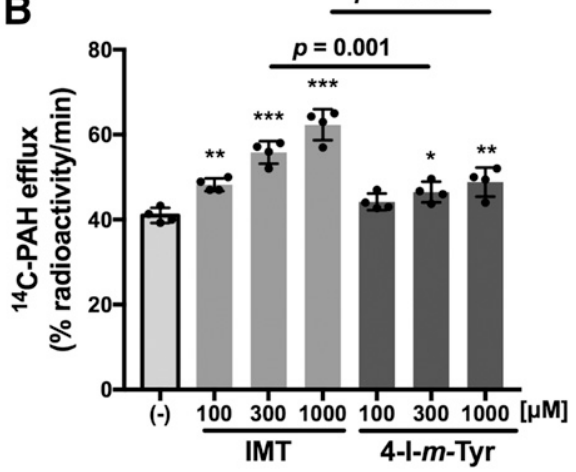

Fig. 3. Comparison of IMT and 4-I-m-Tyr in interaction with OAT1. (A) Concentrationdependent inhibition of $\left[{ }^{14} \mathrm{C}\right] \mathrm{PAH}$ uptake by IMT and 4 -I- $m$-Tyr in OAT 1 cells. Uptake of $\left[{ }^{14} \mathrm{C}\right] \mathrm{PAH}(1 \mu \mathrm{M})$ was measured in the presence of varied concentrations of IMT or 4 -I- $m$-Tyr. Uptake values were fitted to inhibition curves with $\mathrm{IC}_{50}$ listed in Table 1. (B) $\left[{ }^{14} \mathrm{C}\right] \mathrm{PAH}$ efflux mediated by OAT1 induced by IMT and 4 -I- $m$-Tyr. The efflux of preloaded $\left[{ }^{14} \mathrm{C}\right] \mathrm{PAH}$ from OAT1 cells was measured for 1 minute in the presence or absence (-) of extracellular compounds at the indicated concentration. The radioactivity released from the cells was expressed as the percentage of total preloaded radioactivity. ${ }^{*} P<0.05$; $* * P<0.01 ; * * * P<0.001$ vs. ( - ). Data are expressed as means \pm S.D. $(n=4)$.
$[\operatorname{Dox}(+)]$ and nonexpressing [Dox $(-)]$ cells was obtained by incubating the cells with $\left[{ }^{14} \mathrm{C}\right] \mathrm{PAH}$ at the concentrations predetermined individually for Dox $(+)$ and Dox $(-)$ cells (Supplemental Fig. 2, A and B). As depicted in Supplemental Fig. 2C, extracellular PAH induced substantial efflux of preloaded $\left[{ }^{14} \mathrm{C}\right] \mathrm{PAH}$ in Dox $(+)$ cells, whereas PAH did not induce efflux in Dox $(-)$ cells. This confirmed that the efflux of $\left[{ }^{14} \mathrm{C}\right] \mathrm{PAH}$ induced by extracellular $\mathrm{PAH}$ was mediated by OAT1.

OAT1-Mediated $\left[{ }^{14}\right.$ C]FAMT Transport. The interaction of FAMT with OAT1 was first examined in the inhibition experiment, in which the uptake of $\left[{ }^{14} \mathrm{C}\right] \mathrm{PAH}(1 \mu \mathrm{M})$ was measured in the presence of various concentrations of FAMT. As shown in Fig. 2A, FAMT inhibited OAT1-mediated $\left[{ }^{14} \mathrm{C}\right]$ $\mathrm{PAH}$ uptake concentration dependently $\left(\mathrm{IC}_{50}\right.$ value listed in Table 1). Then, the transport of FAMT was evaluated by efflux experiments. FAMT concentration dependently induced the efflux of $\left[{ }^{14} \mathrm{C}\right] \mathrm{PAH}$ preloaded into the cells, suggesting that extracellular FAMT is transported by OAT1 in exchange for preloaded [ $\left.{ }^{14} \mathrm{C}\right] \mathrm{PAH}$ (Fig. 2B). The transport of FAMT was confirmed by direct transport assay using $\left[{ }^{14} \mathrm{C}\right] \mathrm{FAMT} .\left[{ }^{14} \mathrm{C}\right]$
FAMT was transported by OAT1 with a $K_{\mathrm{m}}$ value of $171.9 \pm$ $16.6 \mu \mathrm{M}(n=4)$ (Fig. 2C).

Interactions of IMT and 4-I-m-Tyr with OAT1. The interactions of IMT and 4-I- $m$-Tyr with OAT1 were studied in inhibition and efflux experiments. Both compounds inhibited OAT1-mediated [ $\left.{ }^{14} \mathrm{C}\right] \mathrm{PAH}$ uptake in OAT1 cells concentration dependently, although IMT showed $~ 6$-fold lower $\mathrm{IC}_{50}$ compared with 4-I- $m$-Tyr (Fig. 3A; Table 1). IMT induced efflux of preloaded $\left[{ }^{14} \mathrm{C}\right] \mathrm{PAH}$, suggesting that IMT is transported by OAT1 (Fig. 3B). Consistent with the inhibition experiments, a smaller efflux was induced by 4 -I- $m$-Tyr as compared with IMT (Fig. 3B).

The Roles of $\alpha$-Methyl, Hydroxyl, and Halogen Groups of IMT and FAMT in Interaction with OAT1. To determine which chemical features of IMT are necessary for interaction with OAT1, the roles of the $\alpha$-methyl, hydroxyl, and halogen groups, which differ between IMT and 4-I- $m$-Tyr, were examined. In the comparisons of IMT with 3-I-AMP and AMT, the removal of either the hydroxyl or halogen group of IMT decreased the magnitude of the inhibition of OAT1mediated $\left[{ }^{14} \mathrm{C}\right] \mathrm{PAH}$ uptake, as well as the induction of $\left[{ }^{14} \mathrm{C}\right]$

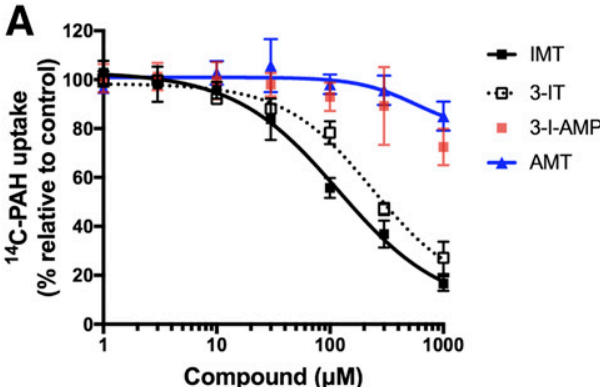

C

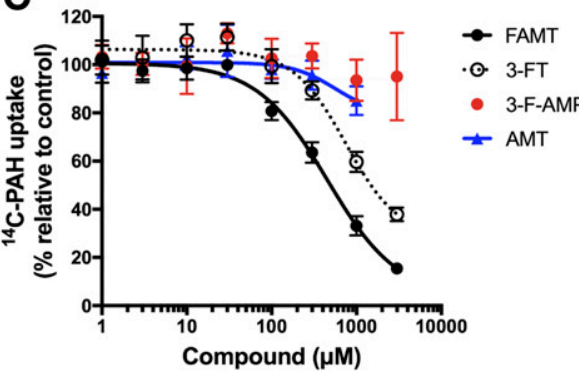

B

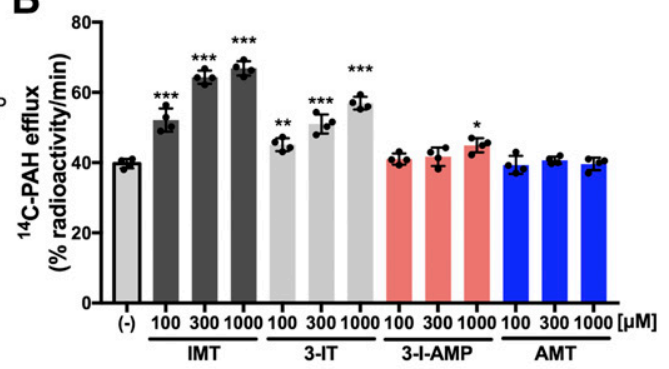

D

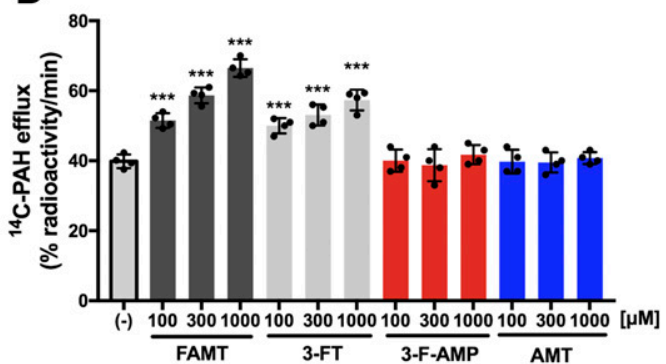

Fig. 4. Effect of removal of the $\alpha$-methyl, hydroxyl, or halogen group from IMT and FAMT. The concentration-dependent inhibition of $\left[{ }^{14} \mathrm{C}\right] \mathrm{PAH}$ uptake $(\mathrm{A})$ and the induction of OAT1-mediated $\left[{ }^{14} \mathrm{C}\right] \mathrm{PAH}$ efflux (B) were compared among IMT and the compounds (3-IT, 3-I-AMP, and AMT) in which the $\alpha$-methyl, hydroxyl, or halogen group was removed from IMT. The effect of removal of the $\alpha$-methyl, hydroxyl, and halogen groups was also examined for FAMT in the comparison with 3-FT, 3-F-AMP, and AMT: the inhibition of $\left[{ }^{14} \mathrm{C}\right] \mathrm{PAH}$ uptake (C); the induction of $\left[{ }^{14} \mathrm{C}\right] \mathrm{PAH}$ efflux (D). The inhibition and efflux experiments were performed as described in the legend to Fig. 3. Uptake values were fitted to inhibition curves except 3-F-AMP and 3I-AMP, which were difficult to fit (A and C). AMT in (C), same as that in (A), is shown as comparison. In (B and D), $* P<$ $0.05 ; * * P<0.01 ; * * * P<0.001$ vs. $(-)$. Data are expressed as means \pm S.D. $(n=4)$. 
A
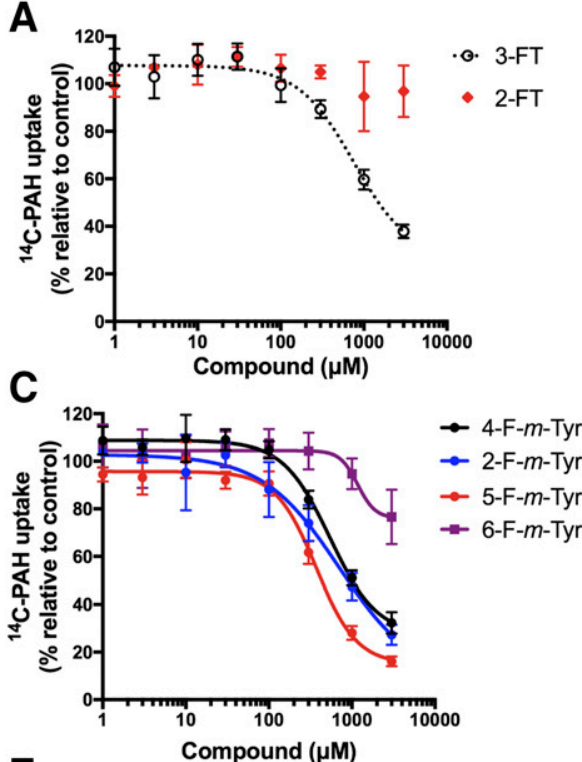

E

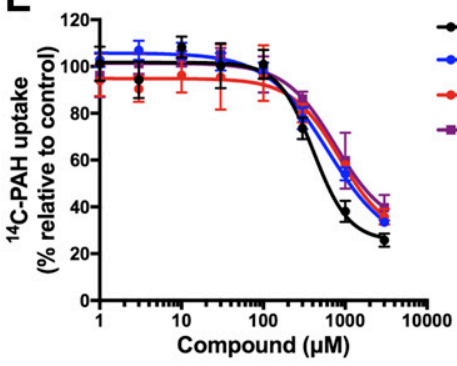

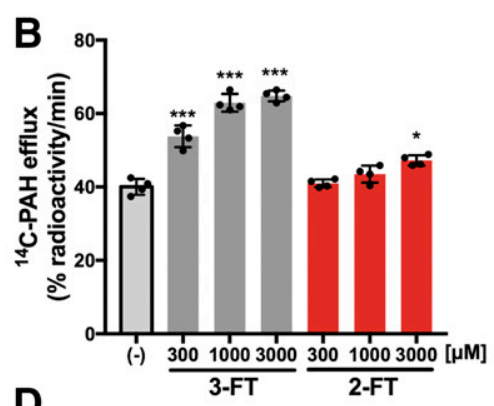

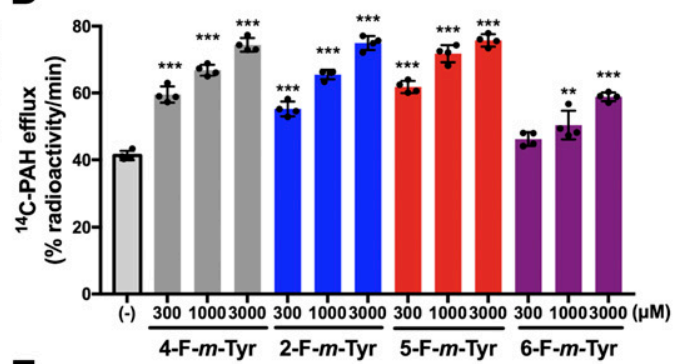

$\mathbf{F}$

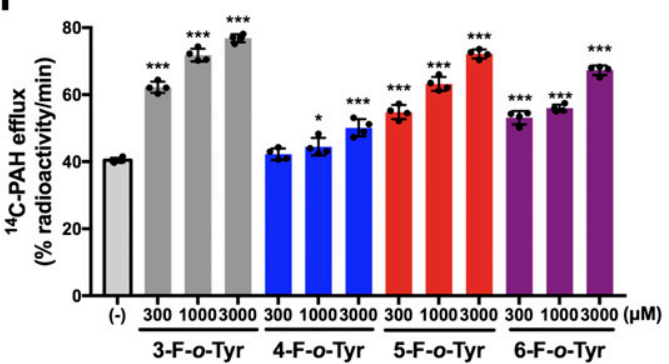

Fig. 5. Effect of fluoro group position in para-tyrosine, meta-tyrosine, and orthotyrosine. The effect of fluoro group position was examined with a hydroxyl group fixed at position 4 (para-position), position 3 (meta-position), or position 2 (ortho-position) of the benzene ring. The concentrationdependent inhibition of $\left[{ }^{14} \mathrm{C}\right] \mathrm{PAH}$ uptake (A, C, and E) and the induction of OAT1mediated $\left[{ }^{14} \mathrm{C}\right] \mathrm{PAH}$ efflux $(\mathrm{B}, \mathrm{D}$, and $\mathrm{F})$ were compared between the compounds at indicated concentrations. The inhibition and efflux experiments were performed as described in the legend to Fig. 3. In (A, C, and E), the uptake values were fitted to inhibition curves, except 2 FT, which was difficult to fit. 3-FT in (A), same as that in Fig. $4 \mathrm{C}$, is shown for comparison. In $(\mathrm{B}, \mathrm{D}$, and $\mathrm{F}),{ }^{*} P<0.05$; $* * P<0.01 ; * * * P<0.001$ vs. $(-)$. Data are expressed as means \pm S.D. $(n=4)$.
PAH efflux mediated by OAT1 (Fig. 4, A and B). In the comparison between IMT and 3-IT, the influence of the removal of $\alpha$-methyl group of IMT was smaller than that of the hydroxyl or halogen group on inhibition and efflux (Fig. 4, $\mathrm{A}$ and $\mathrm{B})$, although it still increased the $\mathrm{IC}_{50}$ value by 2.0 -fold (Table 1). Similar results were also obtained for FAMT, as the removal of either the hydroxyl or halogen group from FAMT largely reduced the interaction with OAT1 in both inhibition and efflux experiments (the comparisons of FAMT with 3-FAMP and AMT in Fig. 4, C and D). The removal of the $\alpha$-methyl group from FAMT also had smaller effects than the removal of hydroxyl or halogen group in the comparison between FAMT and 3-FT (Fig. 4, C and D), although its removal increased the $\mathrm{IC}_{50}$ value by 1.7 -fold, similar to that of IMT (Table 1).

The Positions of the Hydroxyl and Fluoro Groups Required for Interaction with OAT1. The necessity of the positions of the hydroxyl and halogen groups on the benzene ring for interaction with OAT1 was examined in a series of fluorinated tyrosine regioisomers without an $\alpha$-methyl group. Because both 3-fluoro and 4-hydroxyl groups were critical (Fig. 4), the 4-hydroxyl group was fixed in the para-tyrosine configuration, and the effect of the position of the fluoro group was examined in the first series of experiments. As shown in Fig. 5, A and B, the position of the fluoro group had a large influence on the interaction with OAT1 in both inhibition and efflux experiments. Compared with 3-FT, 2-FT exhibited remarkably decreased inhibition on OAT1-mediated $\left[{ }^{14} \mathrm{C}\right]$ $\mathrm{PAH}$ uptake and decreased induction of $\left[{ }^{14} \mathrm{C}\right] \mathrm{PAH}$ efflux (Fig. 5, A and B).
In the second series of experiments, the position of the hydroxyl group was fixed at position 3 (meta-tyrosine configuration), and the fluoro group position was altered on the benzene ring. When the fluoro group was at position 6 on the meta-tyrosine, the compound (6-F-m-Tyr) exhibited decreased inhibition on OAT1-mediated $\left[{ }^{14} \mathrm{C}\right] \mathrm{PAH}$ uptake as well as decreased induction of $\left[{ }^{14} \mathrm{C}\right] \mathrm{PAH}$ efflux compared with $2-\mathrm{F}$ $m$-Tyr, 4-F- $m$-Tyr, and 5-F- $m$-Tyr, which have a fluoro group at positions 2,4 , or 5 , respectively (Fig. $5, \mathrm{C}$ and D).

In the third series of experiments, the position of the hydroxyl group was fixed at position 2 (ortho-tyrosine configuration), and the fluoro group position was altered on the benzene ring. Compounds with a fluoro group at different positions on ortho-tyrosine (3-F-o-Tyr, 4-F-o-Tyr, 5-F-o-Tyr, and 6-F-o-Tyr) exhibited a similar magnitude of inhibition on OAT1 (Fig. 5E). Consistent with this, all four of these compounds induced OAT1-mediated efflux, although the efflux induced by 4-F-o-Tyr was relatively small compared with that induced by the other compounds (Fig. 5F).

Comparison of Iodo and Fluoro Groups in Interaction with OAT1. Because IMT exhibited a decreased $\mathrm{IC}_{50}$ value in the inhibition of OAT1-mediated $\left[{ }^{14} \mathrm{C}\right] \mathrm{PAH}$ uptake and lower $K_{\mathrm{m}}$ in the induction of $\left[{ }^{14} \mathrm{C}\right] \mathrm{PAH}$ efflux compared with FAMT (Table 1), the effect of fluorine-to-iodine substitution was examined in the interaction with OAT1. When the halogen group was located at position 2 on the benzene ring (with a 4-hydroxyl group), the halogen group, whether it was iodine or fluorine, had a profound effect on inhibition and efflux (Fig. 6, A and B). 2-FT did not inhibit OAT1 at the concentrations tested (Fig. 6A). Consistent with this, the 

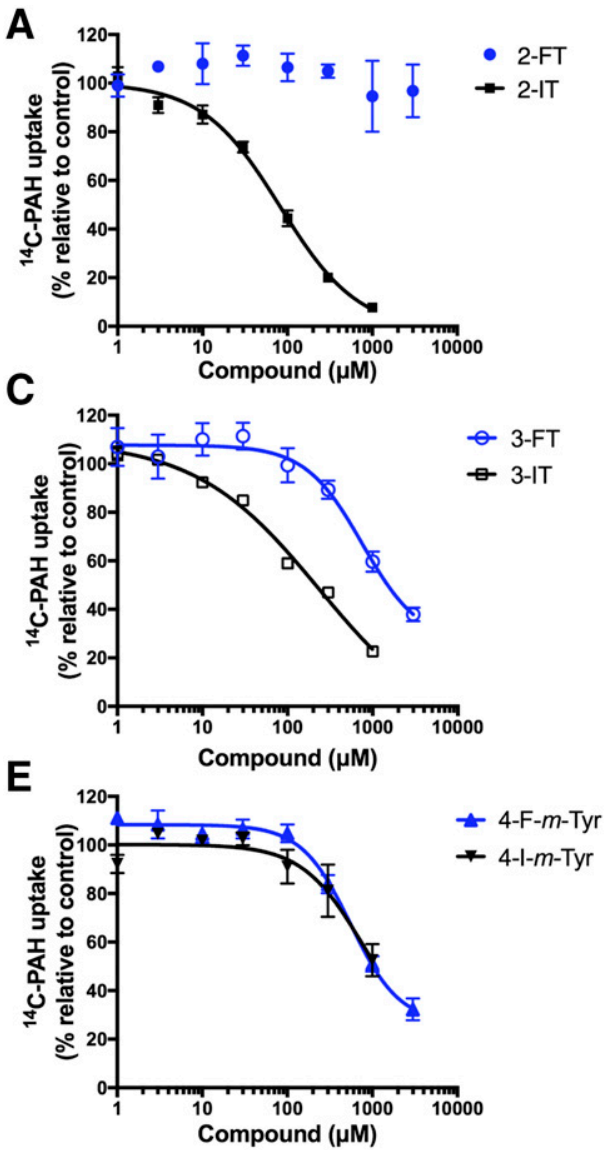
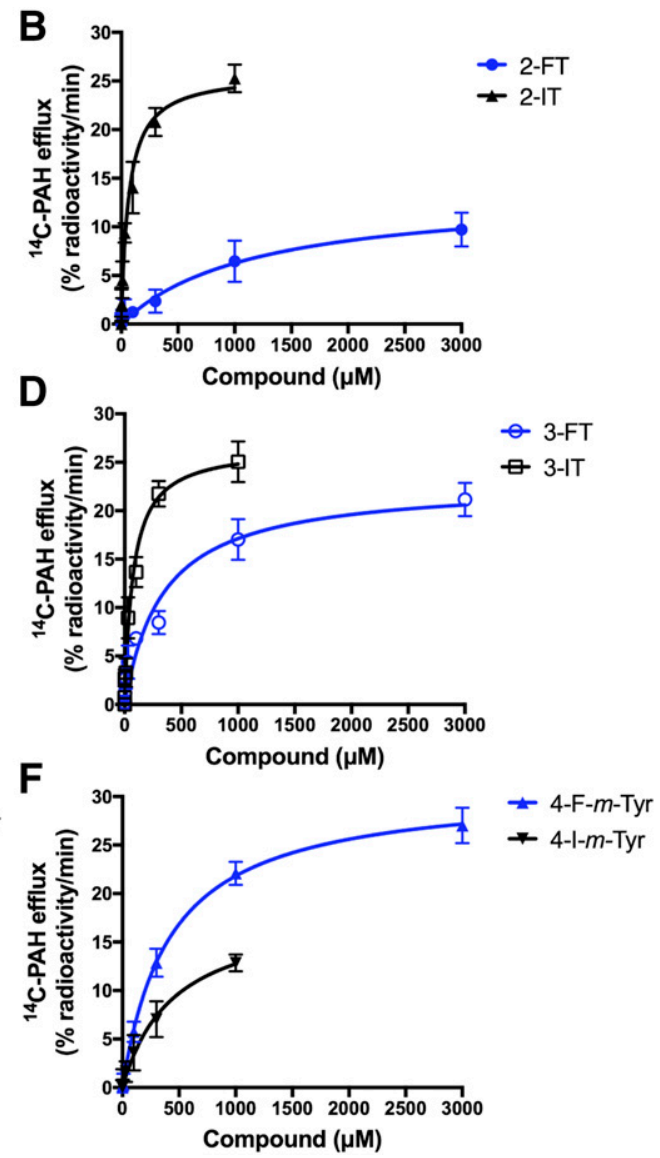

Fig. 6. Comparison of fluoro and iodo groups in the interaction with OAT1. The contribution of fluoro and iodo groups in the interaction with OAT1 was compared between the compound with fluoro group and that with iodo group at the same position: 2-FT and 2-IT (A); 3-FT and 3-IT (B); 4-F- $m$-Tyr and 4-I- $m$-Tyr (A). The inhibition of $\left[{ }^{14} \mathrm{C}\right] \mathrm{PAH}$ uptake $(\mathrm{A}, \mathrm{C}$, and $\mathrm{E})$ and the induction of OAT1-mediated $\left[{ }^{14} \mathrm{C}\right] \mathrm{PAH}$ efflux (B, D, and F) were examined as described in the legend to Fig. 3. In (A, C, and E), the uptake values were fitted to inhibition curves, whereas the efflux values are fitted to MichaelisMenten curves in (B, D, and F). Blue: compounds with a fluoro group; black: compounds with an iodo group. In (A, C, and $\mathrm{E}$ ), the compounds, except 2-IT, were presented in the other figures and shown for comparison (2-FT from Fig. 5; 3-FT and 3-IT from Fig 4; 4-F-m-Tyr from Fig 5; 4-I-m-Tyr from Fig. 3). Data represent means \pm S.D., $n=4$. efflux induced by 2 -FT was much reduced compared with that induced by 2-IT (Fig. 6B). When the halogen group was at position 3 on the benzene ring (with a 4-hydroxyl group), the impact of iodine or fluorine on the interaction with OAT1 was reduced compared with a halogen at position 2 (Fig. 6, $\mathrm{C}$ and D). $\mathrm{IC}_{50}$ of 3 -FT was 3.2 -fold higher than that of 3 -IT in inhibition experiments, whereas the $K_{\mathrm{m}}$ of 3 -FT in the induction of $\left[{ }^{14} \mathrm{C}\right] \mathrm{PAH}$ efflux was 4.6 -fold higher than that of 3 IT (Table 1). Finally, when the halogen group was at position 4 (with a 3-hydroxyl group), the $\mathrm{IC}_{50}$ and $K_{\mathrm{m}}$ values of $4-\mathrm{F}-m-\mathrm{Tyr}$ were similar to those of 4 -I- $m$ Tyr; $\mathrm{IC}_{50}$ and $K_{\mathrm{m}}$ of $4-\mathrm{F}-m-\mathrm{Tyr}$ were 0.72 -fold and 0.93 -fold of $\mathrm{IC}_{50}$ and $K_{\mathrm{m}}$ of 4 -I- $m \mathrm{Tyr}$, respectively (Fig. 6, E and F; Table 1).
Interactions of 2-FAMT with OAT1, and Amino Acid Transporters LAT1 and LAT2. Because 2-FT interacted the least with OAT1 (Fig. 5A), we expected that 2-FAMT, in which an $\alpha$-methyl group is added to 2-FT to promote LAT1 specificity (Wiriyasermkul et al., 2012; Wei et al., 2016b), might be an LAT1-specific substrate with reduced OAT1 interaction. As shown in Fig. 7, 2-FAMT exhibited decreased inhibition of OAT1-mediated $\left[{ }^{14} \mathrm{C}\right] \mathrm{PAH}$ uptake and induced decreased OAT1-mediated $\left[{ }^{14} \mathrm{C}\right] \mathrm{PAH}$ efflux compared with FAMT.

LAT1-specific transport of 2-FAMT was further confirmed by efflux experiments. 2-FAMT induced LAT1-mediated efflux of preloaded $\left[{ }^{14} \mathrm{C}\right] \mathrm{L}-$ leucine, whereas it did not induce efflux of
A

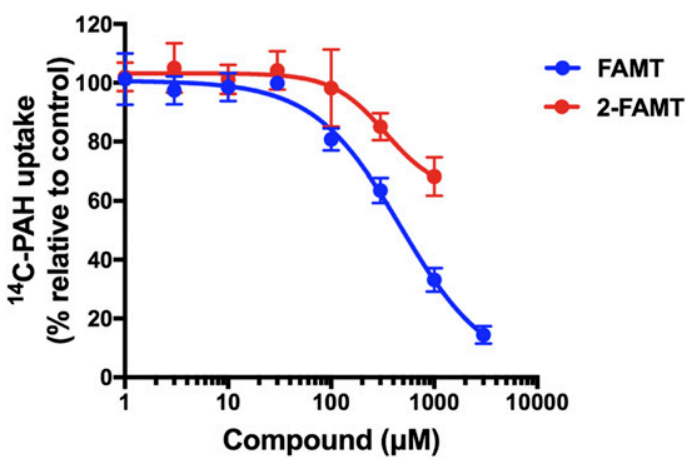

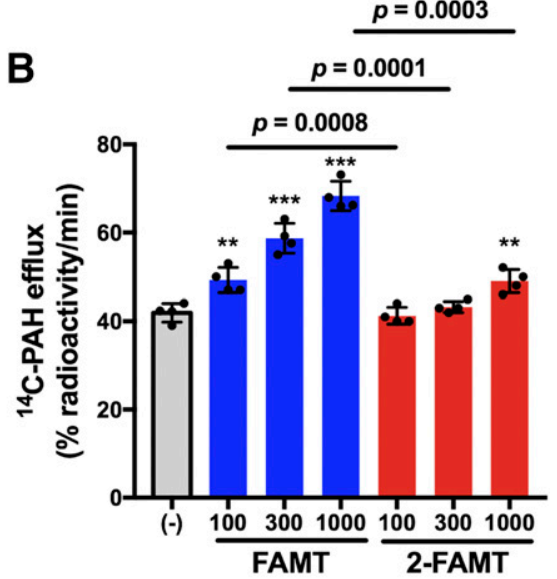

Fig. 7. Interaction of 2-FAMT with OAT1. 2-FAMT, which has a fluoro group at position 2, and FAMT, with a fluoro group at position 3 , were compared in the inhibition of $\left[{ }^{14} \mathrm{C}\right] \mathrm{PAH}$ uptake (A) and the induction of OAT1-mediated $\left[{ }^{14} \mathrm{C}\right] \mathrm{PAH}$ efflux at 100, 300, $1000 \mu$ M. (B). 2-FAMT exhibited less inhibition on OAT1-mediated $\left[{ }^{14} \mathrm{C}\right] \mathrm{PAH}$ uptake than FAMT (A). Similarly, 2-FAMT induced less $\left[{ }^{14} \mathrm{C}\right] \mathrm{PAH}$ efflux mediated by OAT1 compared with FAMT (B). The inhibition and efflux experiments were performed as described in the legend to Fig. 3. FAMT in (A), same as that in Fig. 4C, is shown for comparison. In (B), $* P<0.05 ; * * P<0.01 ; * * * P<0.001$ vs. $(-)$. Data are expressed as means \pm S.D. $(n=4)$. 
A

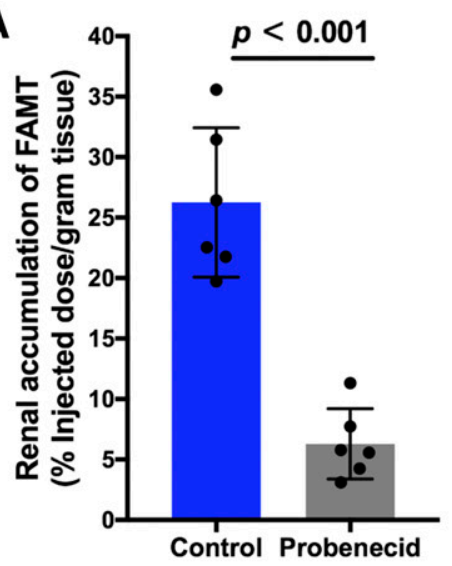

D

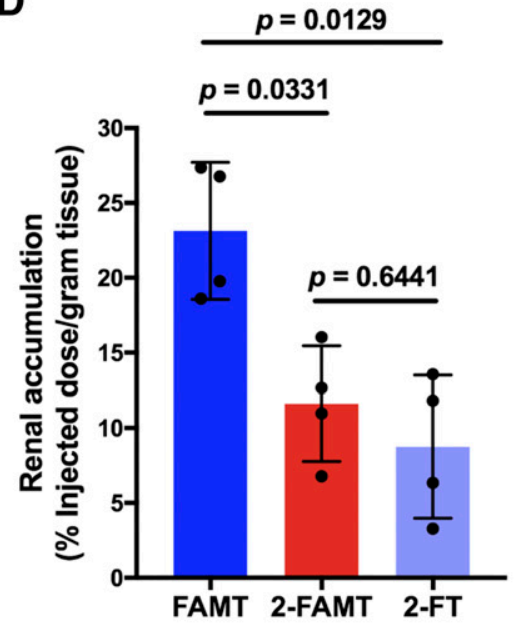

B

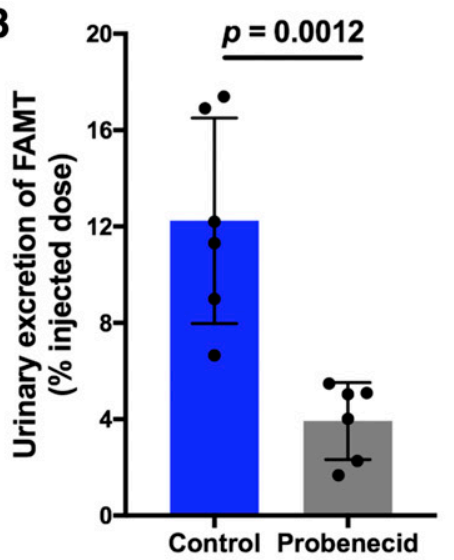

E

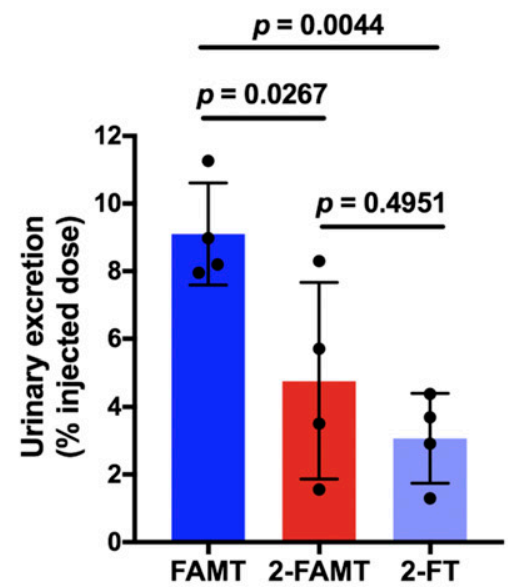

C

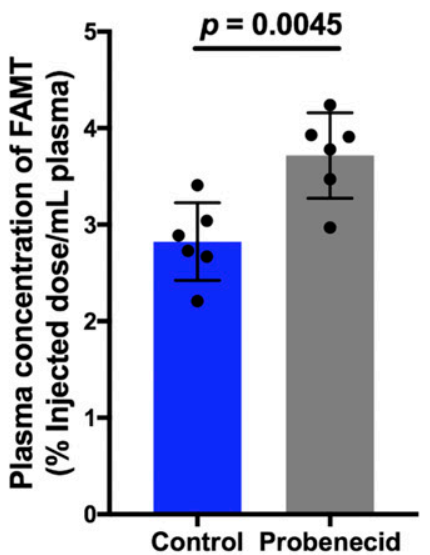

F

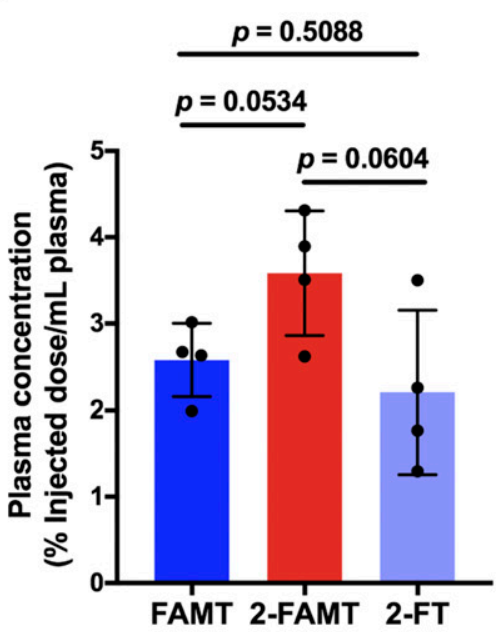

H

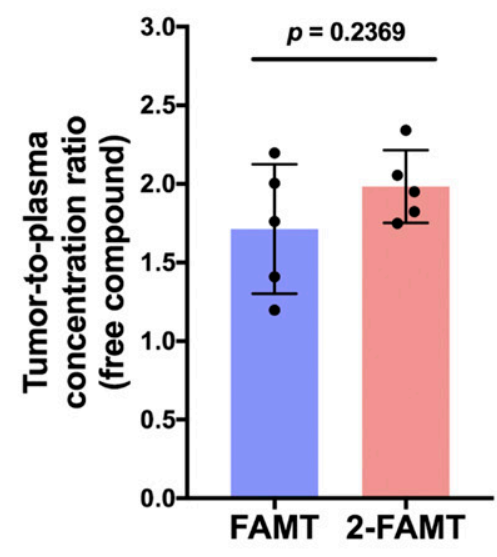

G

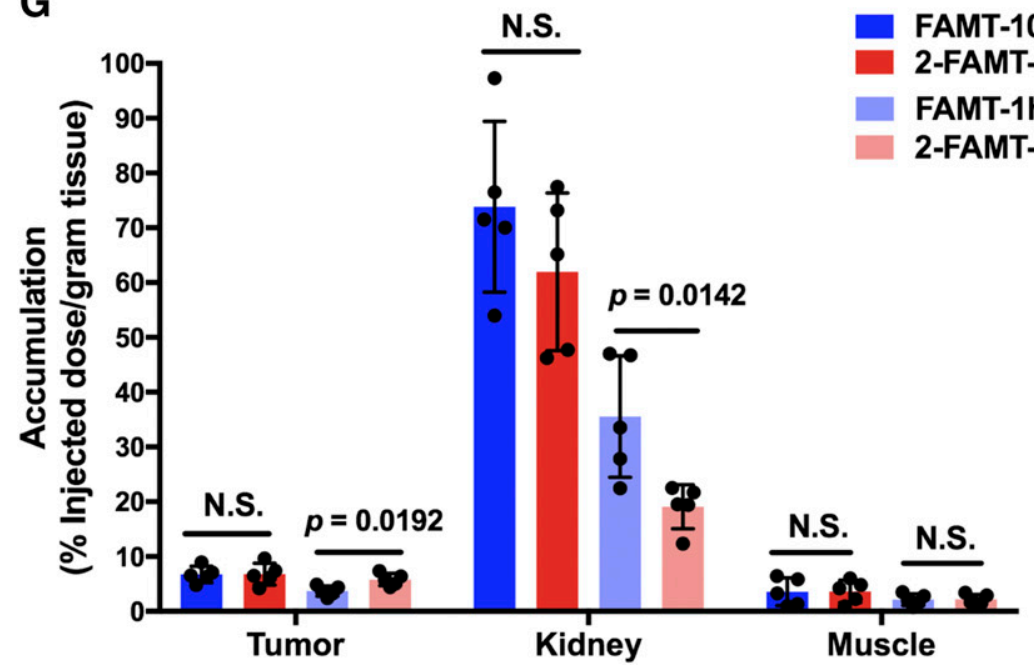

Fig. 8. In vivo studies of FAMT, 2-FAMT, and 2-FT on their renal handling and tumor accumulation. (A-C) The effect of probenecid on renal handling of FAMT in mice. The renal accumulation, urinary excretion, and plasma concentration of FAMT at 10 minutes after the intravenous administration of FAMT $(1.5 \mathrm{mg} / \mathrm{kg})$ were measured with and without probenecid treatment in ddY mice. Probenecid $(50 \mathrm{mg} / \mathrm{kg})$ was preadministered intravenously 10 minutes before the injection of FAMT. Treatment with probenecid reduced renal accumulation (A), decreased urinary excretion (B), and increased plasma concentration (C) of FAMT. (D-F) Comparison of FAMT, 2-FAMT, and 2-FT administered in mice. Renal accumulation, urinary excretion, and plasma concentration were measured at 10 minutes after the intravenous administration of equimolar amounts of FAMT (1.5 mg/kg), 2-FAMT $(1.5 \mathrm{mg} / \mathrm{kg})$, and 2-FT $(1.4 \mathrm{mg} / \mathrm{kg})$ in ddY mice. The renal accumulation (D) and urinary excretion (E) of 2-FAMT and 2-FT were lower than those of FAMT. (G) Comparison of 2-FAMT and FAMT in tumor accumulation. The accumulation of 2-FAMT and FAMT in tumor as well as kidney and skeletal muscle was measured at 10 minutes and 1 hour after the intravenous administration in B16F10 tumor-bearing mice. At 1 hour, 2-FAMT showed accumulation 1.56 times higher compared with FAMT in the tumor, whereas the renal accumulation of 2-FAMT was 0.53 times lower than that of 


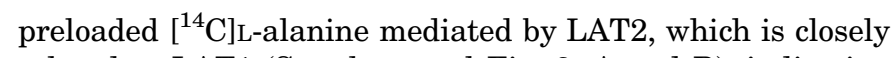
related to LAT1 (Supplemental Fig. 3, A and B), indicating that 2-FAMT was transported by LAT1 but not by LAT2. The LAT1 selectivity of 2-FAMT was similar to that of FAMT, whereas 2-FT, lacking an $\alpha$-methyl group, was transported by both LAT1 and LAT2 (Supplemental Fig. 3, A and B).

Renal Handling and Tumor Accumulation: Comparison of FAMT, 2-FAMT, and 2-FT In Vivo. The involvement of the organic anion transport system in the renal handling of FAMT was examined in vivo using probenecid, an inhibitor of organic anion transporters, including OAT1. In ddY mice intravenously administered FAMT, the probenecid treatment reduced the renal accumulation of FAMT by 80\% $(P<0.001)$ (Fig. 8A) and reduced urinary excretion of FAMT by $66 \%$ compared with the nontreated control $(P=$ 0.0012 ) (Fig. 8B). The plasma concentration of FAMT was, in contrast, increased by probenecid $(P=0.0045)$. This suggests that FAMT is mainly secreted into the urine via a transepithelial organic anion transport system and that the site of action of probenecid may be on the basolateral side, where OAT1 is localized, as discussed in detail later.

Because 2-FT and 2-FAMT showed reduced interaction with OAT1 in vitro (Figs. 5, A and B and 7), we compared their renal accumulation, urinary excretion, and plasma concentration with those of FAMT in vivo. In ddY mice intravenously administered equimolar amounts of FAMT, 2-FAMT, or 2$\mathrm{FT}$, lower renal accumulation and lower urinary excretion were observed after 2-FAMT or 2-FT administration compared with FAMT administration (Fig. 8, D and E). Notably, 2FAMT showed a relatively higher plasma concentration than FAMT, although the difference was not statistically significant (Fig. 8F). In the pharmacokinetic study conducted in mice, 2-FAMT exhibited a lower rate constant of elimination from the plasma $\left(K_{\mathrm{e}}\right)$, and the longer half-life in the plasma compared with FAMT (Table 2). Furthermore, the renal clearance $\left(\mathrm{CL}_{\text {renal }}\right)$ of 2-FAMT was lower than that of FAMT (Table 2).

Because of the low renal accumulation and LAT1-specific transport of 2-FAMT, we examined the tumor accumulation of 2-FAMT and compared it with that of FAMT. In tumorbearing C57BL/6J mice injected intravenously with FAMT or 2-FAMT, the accumulation of 2-FAMT in the tumor was 1.56-fold higher than that of FAMT after 1 hour $(P=0.0192)$ (Fig. 8G). The renal accumulation of 2-FAMT was 0.53 -fold of that of FAMT after 1 hour $(P=0.0142)$. At 10 minutes after administration, no difference was detected between 2-FAMT and FAMT in tumor or in the kidney, nor was any difference observed between FAMT and 2-FAMT accumulation in the skeletal muscle after 10 minutes or 1 hour. FAMT and 2FAMT did not exhibit differences in the tumor-to-plasma concentration ratio of free compounds at 1 hour estimated
TABLE 2

Pharmacokinetic parameters of FAMT and 2-FAMT in ddY mice

\begin{tabular}{lccc}
\hline Pharmacokinetic Parameters & \multicolumn{1}{c}{ FAMT } & \multicolumn{1}{c}{ 2-FAMT } & $P$ Value $^{a}$ \\
\hline $\mathrm{AUC}_{0-\infty}(\mathrm{h} \cdot \mu \mathrm{M})^{b}$ & $49.23 \pm 8.42^{c}$ & $60.24 \pm 12.15$ & 0.0806 \\
$K_{\mathrm{e}}\left(\mathrm{h}^{-1}\right)^{d}$ & $1.07 \pm 0.13$ & $0.86 \pm 0.10$ & 0.0131 \\
$t_{1 / 2}(\mathrm{~h})^{e}$ & $0.65 \pm 0.08$ & $0.81 \pm 0.11$ & 0.0131 \\
$A \mathrm{e}_{0-\infty}(\mathrm{nmol})^{f}$ & $114.52 \pm 7.73$ & $106.4 \pm 13.48$ & 0.0487 \\
$\mathrm{CL}_{\text {renal }}(\mathrm{l} / \mathrm{h} \text { per kilogram })^{g}$ & $2.39 \pm 0.86$ & $1.85 \pm 0.38$ & 0.0413 \\
\hline
\end{tabular}

${ }^{a}$ FAMT vs. 2-FAMT

${ }^{b} \mathrm{AUC}_{0-\infty}$, area under the plasma concentration-time curve from time zero to infinity.

${ }^{c}$ Values represent means \pm S.D. $(n=4-6)$

${ }^{d}$ The elimination rate constant $\left(K_{\mathrm{e}}\right)$ of FAMT and 2-FAMT was determined following the formula: $\operatorname{lnC}_{\mathrm{t}}=\operatorname{lnC}_{0}-K_{\mathrm{e}} \times t\left(\mathrm{C}_{\mathrm{t}}\right.$, concentration at time $t ; \mathrm{C}_{0}$, initial concentration).

${ }^{e} t_{1 / 2}$, elimination half-life; $t_{1 / 2}=\ln 2 / K_{\mathrm{e}}$.

${ }_{A \mathrm{e}_{0-\infty}, \text { total amount of compounds excreted into urine. }}$

${ }^{g}$ The renal clearance $\left(\mathrm{CL}_{\text {renal }}\right)$ of FAMT and 2-FAMT was obtained by dividing $A \mathrm{e}_{0-\infty}$ by $\mathrm{AUC}_{0-\infty}$.

based on the protein-unbound free compound fraction $\left(f_{\mathrm{u}}\right)$ obtained in vitro (Fig. $8 \mathrm{H}$ ).

\section{Discussion}

In the present study, we demonstrated that FAMT is transported by renal organic anion transporter OAT1 concentration dependently (Fig. 2). To optimize the halogenated compounds that exhibit low interaction with OAT1 and high specificity for LAT1-mediated transport, we investigated the structural requirements of FAMT for interaction with OAT1. On the basis of previous reports showing remarkably decreased renal accumulation of 4-I- $m$-Tyr compared with IMT, which is structurally identical to FAMT except for a fluorine/ iodine substitution (Shikano et al., 2003), we found that 4-I$m$-Tyr interacted less with OAT1 than IMT did in both inhibition and efflux studies (Fig. 3). In comparing distinct structures, the 3-halogen and 4-hydroxyl groups of IMT and FAMT were essential for interaction with OAT1, whereas the $\alpha$-methyl group contributed to a lesser extent, but it was still relevant (Fig. 4; Table 1 ).

It has been proposed that the preferred substrates of $\mathrm{PAH}$ transporter at the basolateral membrane of renal proximal tubules, where OAT1 is located, contain hydrophobic cores with negative ionic or partial charges (Ullrich and Rumrich, 1988). These requirements were confirmed for OAT1 (Apiwattanakul et al., 1999). The binding of organic anions would thus depend on both hydrophobic and electrostatic interactions (Møller and Sheikh, 1982; Fritzsch et al., 1989). Because the presence of the $\alpha$-methyl group decreased $\mathrm{IC}_{50}$ values for both IMT and FAMT (Table 1), the $\alpha$-methyl group was hypothesized to be involved in the makeup of the hydrophobic core. The ortho-position of the benzene ring, close to the $\alpha$-methyl

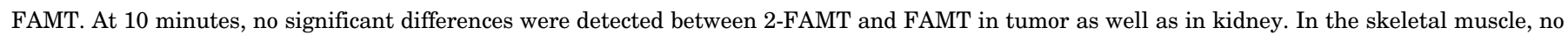

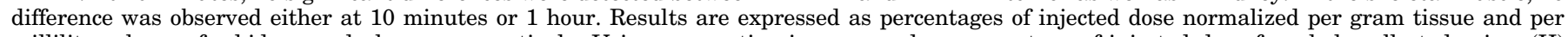

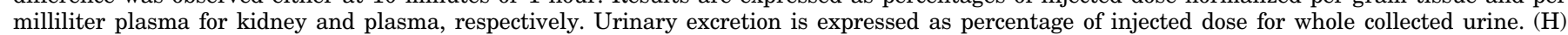

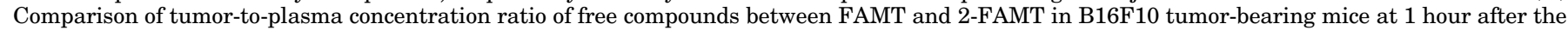

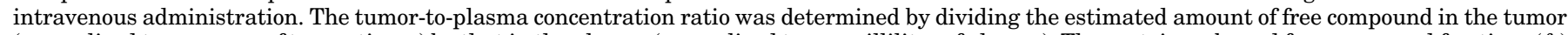

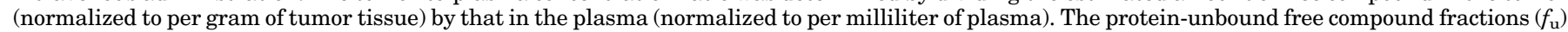

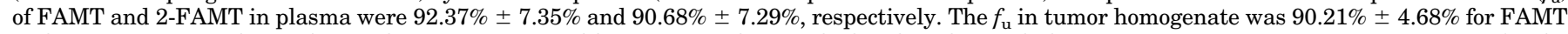

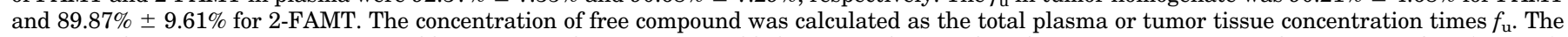

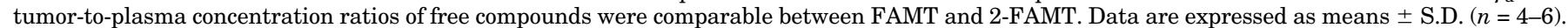
N.S., no statistically significant difference between FAMT and 2-FAMT. 
group, may also be located in the central part of the hydrophobic core because the substitution of fluorine with a bulky, hydrophobic iodine atom at the ortho-position dramatically increased the interaction with OAT1 (Fig. 6, A and B). This influence is reduced at the meta-position (Fig. 6, C and D) and is almost negligible at the para-position (Fig. 6, E and F). The paraposition would thus represent the margin of the effective hydrophobic core. This hypothesis is consistent with the preferred size of hydrophobic core, which has been proposed to be 6-10 $\AA$ in the renal PAH transport (Fritzsch et al., 1989), because the distance from the carbonyl carbon of the $\alpha$-carboxyl group to the fluoro/iodo group at the ortho-, meta-, and parapositions are estimated to be $4.45 / 4.62,6.92 / 7.52$, and 7.94/8.69 $\AA$, respectively (Supplemental Fig. 4).

As negative ionic or partial charges are required for substrate binding (Ullrich and Rumrich, 1988), the $\alpha$-carboxyl group is considered to have a negative ionic charge. Furthermore, the hydroxyl group on the benzene ring, necessary for interaction with OAT1, may behave as an additional negative partial charge because the $\mathrm{p} K_{\mathrm{a}}$ of a phenolic hydroxyl group is inversely related to the interaction with the $\mathrm{PAH}$ transporter (Fritzsch et al., 1989). The present study confirmed the tendency of an inverse relationship between the inhibitory activity of the compound and the estimated $\mathrm{p} K_{\mathrm{a}}$ of the hydroxyl group on the benzene ring (Supplemental Fig. 5). The role of the halogen group, which is also necessary, is further proposed to stabilize or increase the negative partial charge of the hydroxyl group because of the electron attraction, which lowers the $\mathrm{p} K_{\mathrm{a}}$ of the hydroxyl group on the benzene ring. In the absence of the halogen group, the negative partial charge of the hydroxyl group would not be enough to interact with OAT1 (Table 1).

Intriguingly, the hydroxyl group may be localized at any position on the benzene ring and still maintain interaction with OAT1 (Fig. 5). Because of the mutual structural adjustments of substrates and the binding site, the hydroxyl group, whether it is at ortho-, meta-, or para-positions, may be located to the negative charge recognition site, whereas the $\alpha$-carboxyl group is placed at the other negative charge recognition site (Supplemental Fig. 6, A-C). The hydrophobic core involving a fluorine at any position may be accepted by the hydrophobic pocket in the binding site (Fritzsch et al., 1989) when the hydroxyl group is at the ortho-position (Fig. 5, E and F; Supplemental Fig. 6A). By contrast, the distance between the hydrophobic core of the substrate and the bottom of the hydrophobic pocket would be increased when the hydroxyl group is at the meta- or para-position (Supplemental Fig. 6, B and $\mathrm{C}$ ). The vacant space formed between the hydrophobic core and the hydrophobic pocket may be more prominent when fluorine is at the ortho-position (Supplemental Fig. 6, $\mathrm{B}$ and $\mathrm{C}$ ) because 2-FT and 6-F-m-Tyr showed reduced interaction (Fig. 5). This vacant space could be filled with the bulkier iodine because the replacement of fluorine with iodine at the ortho-position dramatically increased the interaction (Fig. 6, A and $\mathrm{B}$ ).

As a candidate of halogenated compound with low interaction with OAT1 and high LAT1 specificity, we examined 2FAMT, in which the $\alpha$-methyl group, which provides LAT1 specificity (Wiriyasermkul et al., 2012; Wei et al., 2016b), is added to $2-\mathrm{FT}$, which demonstrated the least interaction with OAT1. LAT1-selective transport of 2-FAMT was confirmed in comparison with FAMT and 2-FT (Supplemental Fig. 3). As expected, 2-FAMT exhibited less interaction with OAT1 compared with FAMT (Fig. 7; Supplemental Fig. 7).

In in vivo experiments that address the renal handling, both renal accumulation and urinary excretion of FAMT were suppressed by probenecid, whereas the plasma concentration was increased (Fig. 8, A and C), suggesting that FAMT is excreted into urine mainly via transepithelial transport in the basolateral-to-apical direction. This observation is consistent with previous studies showing that renal accumulation and urinary excretion of IMT were decreased by probenecid (Shikano et al., 2004b; Nakajima et al., 2007). Transepithelial organic anion excretion is an accumulative process in which the intracellular concentration of organic anions can rise to 100-300 times the concentration in the peritubular fluid because organic anion transporters, including OAT1, involved in this process mediate tertiary active transport (Schäli and Roch-Ramel, 1980; Shikano et al., 2004a); this may account for the renal accumulation of FAMT in the course of transepithelial transport.

The effects of probenecid on the renal accumulation, urinary excretion, and plasma concentration of FAMT suggest that the primary site of action of probenecid is the basolateral side of the proximal tubules, although probenecid blocks organic anion transporters involved in uptake and efflux on both the apical and basolateral membrane of proximal tubules (Brazeau, 1975; Pelis and Wright, 2011). We previously showed that, among organic ion transporters mediating uptake into tubular epithelial cells, OAT1, OAT10, and OCTN2 transported FAMT, whereas OAT3, OAT4, URAT1, OCTN1, OCT1, and OCT2 did not transport FAMT (Wei et al., 2016a). Reduced transport of FAMT by OAT3 was confirmed in the present study, along with 2-FAMT and 2-FT (Supplemental Fig. 7). Because OAT3 preferentially transports compounds with larger molecular size and larger nonpolar surface area compared with OAT1, FAMT-related compounds may not be preferable substrates of OAT3 (Astorga et al., 2011). Although OAT2, mainly expressed in the liver in humans, was not examined in our study, the contribution of OAT2 to FAMT transport may be less plausible because of the negligible liver accumulation of FAMT observed via $\left[{ }^{18} \mathrm{~F}\right] \mathrm{FAMT}-\mathrm{PET}$ imaging (Inoue et al., 2001; Vildhede et al., 2018; Hanaoka et al., 2019). Among OAT1, OAT10, and OCTN2, the basolateral membrane transporter OAT1 is involved in the transepithelial accumulative organic anion excretion in the basolateral-toapical direction (Anzai et al., 2006). Therefore, OAT1 is supposed to be the most important transporter responsible for the high renal background of tumor-specific amino acid tracers, such as $\left[{ }^{18} \mathrm{~F}\right] \mathrm{FAMT}$ and $\left[{ }^{123} \mathrm{I}\right] \mathrm{IMT}$.

Consistent with the proposed role of OAT1 in the renal handling of FAMT and related compounds, 2-FAMT and 2-FT showed reduced interaction with OAT1 (Figs. 5 and 7) and exhibited less renal accumulation and urinary excretion compared with FAMT (Fig. 8, D and E). In the pharmacokinetic study, we confirmed that the $\mathrm{CL}_{\text {renal }}$ of 2-FAMT was lower than that of FAMT (Table 2). As indicated above, 2FAMT is LAT1-selective, whereas 2-FT is not (Supplemental Fig. 3). Therefore, we examined the tumor accumulation of 2FAMT in tumor-bearing mice and found that 2-FAMT exhibited higher tumor uptake with less renal accumulation compared with FAMT (Fig. 8G). Because the tumor-to-plasma ratio of 2-FAMT was not different from that of FAMT (Fig. $8 \mathrm{H}$ ), the higher tumor accumulation of 2-FAMT would 
be due to the higher plasma exposure compared with FAMT (Fig. 8F; Table 2). Increased tumor uptake upon inhibition of renal accumulation and urinary excretion was also demonstrated by IMT (Nakajima et al., 2007). Additionally, 2-fluoro$\alpha$-methyl-L-phenylalanine, lacking a ring-hydroxyl group and so presumably less interactive with OAT1, has been shown to have higher tumor uptake and lower renal accumulation than FAMT (Hanaoka et al., 2019). These observations suggest that reducing the interaction with OAT1 may be beneficial to improve tumor targeting as well as to suppress renal accumulation. Such a strategy could also be useful for targeted alpha therapy. In this respect, ${ }^{211} \mathrm{At}$-labeled $\alpha$-methyl phenylalanine would be a preferable candidate for cancer-specific targeted alpha therapy that causes less renal damage. The $\alpha$-methyl tyrosine with ortho- ${ }^{211}$ At should be avoided because the bulky ${ }^{211} \mathrm{At}$ atom would likely increase the interaction with OAT1 (Fig. 6). The present study would also support the use of para- $\left[{ }^{211}\right.$ At $]$ phenylalanine (Watabe et al., 2020), which exhibited remarkable antitumor effects in mice with less obvious toxicity.

\section{Authorship Contributions}

Participated in research design: Jin, Ohgaki, Okuda, Okanishi, He, Nagamori, Kanai.

Conducted experiments: Jin, Wei, Ohgaki, Tominaga, Xu, Kawamoto.

Performed data analysis: Jin, Wei, Kanai.

Wrote or contributed to the writing of the manuscript: Jin, Kanai.

\section{References}

Anzai N, Kanai Y, and Endou H (2006) Organic anion transporter family: current knowledge. J Pharmacol Sci 100:411-426.

Apiwattanakul N, Sekine T, Chairoungdua A, Kanai Y, Nakajima N, Sophasan S, and Endou H (1999) Transport properties of nonsteroidal anti-inflammatory drugs by organic anion transporter 1 expressed in Xenopus laevis oocytes. Mol Pharmacol 55:847-854.

Astorga B, Wunz TM, Morales M, Wright SH, and Pelis RM (2011) Differences in the substrate binding regions of renal organic anion transporters 1 (OAT1) and 3 (OAT3). Am J Physiol Renal Physiol 301:F378-F386.

Brazeau P (1975) Inhibitors of tubular transport of organic compounds, in The Pharmacologic Basis of Therapeutics (Goodman L and Gliman A eds) pp 862-863, MacMillan Publishing Co., Inc., New York.

Cook GJ, Maisey MN, and Fogelman I (1999) Normal variants, artefacts and interpretative pitfalls in PET imaging with 18-fluoro-2-deoxyglucose and carbon-11 methionine. Eur J Nucl Med 26:1363-1378.

Fritzsch G, Rumrich G, and Ullrich KJ (1989) Anion transport through the contraluminal cell membrane of renal proximal tubule. The influence of hydrophobicity and molecular charge distribution on the inhibitory activity of organic anions. Biochim Biophys Acta 978:249-256.

Hanaoka H, Ohshima Y, Yamaguchi A, Suzuki H, Ishioka NS, Higuchi T, Arano Y, and Tsushima Y (2019) Novel ${ }^{18} \mathrm{~F}$-labeled $\alpha$-methyl-phenylalanine derivative with high tumor accumulation and ideal pharmacokinetics for tumor-specific imaging. Mol Pharm 16:3609-3616.

Ichida K, Hosoyamada M, Kimura H, Takeda M, Utsunomiya Y, Hosoya T, and Endou H (2003) Urate transport via human PAH transporter hOAT1 and its gene structure. Kidney Int 63:143-155.

Imaoka T, Kusuhara H, Adachi M, Schuetz JD, Takeuchi K, and Sugiyama Y (2007) Functional involvement of multidrug resistance-associated protein 4 (MRP4/ ABCC4) in the renal elimination of the antiviral drugs adefovir and tenofovir. $\mathrm{Mol}$ Pharmacol 71:619-627.

Inoue T, Koyama K, Oriuchi N, Alyafei S, Yuan Z, Suzuki H, Takeuchi K, Tomaru Y, Tomiyoshi K, Aoki J, et al. (2001) Detection of malignant tumors: whole-body PET with fluorine 18 alpha-methyl tyrosine versus FDG--preliminary study. Radiology 220:54-62.

Jager PL, Vaalburg W, Pruim J, de Vries EG, Langen KJ, and Piers DA (2001) Radiolabeled amino acids: basic aspects and clinical applications in oncology. J Nucl Med 42:432-445.

Kanai Y, Segawa H, Miyamoto Ki, Uchino H, Takeda E, and Endou H (1998) Expression cloning and characterization of a transporter for large neutral amino acids activated by the heavy chain of $4 \mathrm{~F} 2$ antigen (CD98). J Biol Chem 273: $23629-23632$.
Kandasamy P, Gyimesi G, Kanai Y, and Hediger MA (2018) Amino acid transporters revisited: new views in health and disease. Trends Biochem Sci 43:752-789.

Møller JV and Sheikh MI (1982) Renal organic anion transport system: pharmacological, physiological, and biochemical aspects. Pharmacol Rev 34:315-358.

Nagamori S, Wiriyasermkul P, Guarch ME, Okuyama H, Nakagomi S, Tadagaki K, Nishinaka Y, Bodoy S, Takafuji K, Okuda S, et al. (2016) Novel cystine transporter in renal proximal tubule identified as a missing partner of cystinuria-related plasma membrane protein rBAT/SLC3A1. Proc Natl Acad Sci USA 113:775-780.

Nakajima S, Shikano N, Kotani T, Ogura M, Nishii R, Yoshimoto M, Yamaguchi N, Iwamura Y, Kubota N, Ishikawa N, et al. (2007) Pharmacokinetics of 3-[ ${ }^{125}$ I] iodoalpha-methyl-L-tyrosine, a tumor imaging agent, after probenecid loading in mice implanted with colon cancer DLD-1 cells. Nucl Med Biol 34:1003-1008.

Ohgaki R, Wei L, Yamada K, Hara T, Kuriyama C, Okuda S, Ueta K, Shiotani M, Nagamori S, and Kanai Y (2016) Interaction of the sodium/glucose cotransporter (SGLT) 2 inhibitor canagliflozin with SGLT1 and SGLT2. J Pharmacol Exp Ther 358:94-102.

Ohshima Y, Hanaoka H, Tominaga H, Kanai Y, Kaira K, Yamaguchi A, Nagamori S, Oriuchi N, Tsushima Y, Endo K, et al. (2013) Biological evaluation of $3-\left[{ }^{(18)} \mathrm{F}\right]$ fluoro- $\alpha$-methyl-D-tyrosine (D-[ ${ }^{(18)}$ F]FAMT) as a novel amino acid tracer for positron emission tomography. Ann Nucl Med 27:314-324.

Pelis RM and Wright SH (2011) Renal transport of organic anions and cations. Compr Physiol 1:1795-1835.

Plathow C and Weber WA (2008) Tumor cell metabolism imaging. J Nucl Med 49 (Suppl 2):43S-63S.

Schäli C and Roch-Ramel F (1980) Accumulation of $\left[{ }^{14} \mathrm{C}\right]$ urate and $\left[{ }^{3} \mathrm{H}\right] \mathrm{PAH}$ in isolated proximal tubular segments of the rabbit kidney. Am $J$ Physiol 239: F222-F227.

Sekine T, Watanabe N, Hosoyamada M, Kanai Y, and Endou H (1997) Expression cloning and characterization of a novel multispecific organic anion transporter. $J$ Biol Chem 272:18526-18529.

Shikano N, Kanai Y, Kawai K, Ishikawa N, and Endou H (2004a) Transport of 99mTc-MAG3 via rat renal organic anion transporter 1. J Nucl Med 45:80-85.

Shikano N, Kawai K, Flores LG II, Nishii R, Kubota N, Ishikawa N, and Kubodera A (2003) An artificial amino acid, 4-iodo-L-meta-tyrosine: biodistribution and excretion via kidney. J Nucl Med 44:625-631.

Shikano N, Kawai K, Nakajima S, Nishii R, Flores LG II, Kubodera A, Kubota N, Ishikawa N, and Saji $\mathrm{H}(2004 \mathrm{~b})$ Renal accumulation and excretion of radioiodinated 3-iodo- $\alpha$-methyl-L-tyrosine. Ann Nucl Med 18:263-270.

Shiraya K, Hirata T, Hatano R, Nagamori S, Wiriyasermkul P, Jutabha P, Matsubara M, Muto S, Tanaka H, Asano S, et al. (2010) A novel transporter of SLC22 family specifically transports prostaglandins and co-localizes with 15hydroxyprostaglandin dehydrogenase in renal proximal tubules. $J$ Biol Chem 285:22141-22151.

Suzuki S, Kaira K, Ohshima Y, Ishioka NS, Sohda M, Yokobori T, Miyazaki T, Oriuchi N, Tominaga H, Kanai Y, et al. (2014) Biological significance of fluorine-18$\alpha$-methyltyrosine (FAMT) uptake on PET in patients with oesophageal cancer. $\mathrm{Br}$ $J$ Cancer 110:1985-1991.

Uchino H, Kanai Y, Kim DK, Wempe MF, Chairoungdua A, Morimoto E, Anders MW, and Endou H (2002) Transport of amino acid-related compounds mediated by L-type amino acid transporter 1 (LAT1): insights into the mechanisms of substrate recognition. Mol Pharmacol 61:729-737.

Ullrich KJ and Rumrich G (1988) Contraluminal transport systems in the proximal renal tubule involved in secretion of organic anions. Am J Physiol 254:F453-F462.

Vildhede A, Kimoto E, Rodrigues AD, and Varma MVS (2018) Quantification of hepatic organic anion transport proteins OAT2 and OAT7 in human liver tissue and primary hepatocytes. Mol Pharm 15:3227-3235.

Watabe T, Kaneda-Nakashima K, Shirakami Y, Liu Y, Ooe K, Teramoto T, Toyoshima A, Shimosegawa E, Nakano T, Kanai Y, et al. (2020) Targeted alpha therapy using astatine ( $\left.{ }^{211} \mathrm{At}\right)$-labeled phenylalanine: a preclinical study in glioma bearing mice. Oncotarget 11:1388-1398.

Wei L, Tominaga H, Ohgaki R, Wiriyasermkul P, Hagiwara K, Okuda S, Kaira K Kato Y, Oriuchi N, Nagamori S, et al. (2016a) Transport of 3-fluoro-L- $\alpha$-methyltyrosine (FAMT) by organic ion transporters explains renal background in $\left[\left(^{18}\right) \mathrm{F}\right]$ FAMT positron emission tomography. J Pharmacol Sci 130:101-109.

Wei L, Tominaga H, Ohgaki R, Wiriyasermkul P, Hagiwara K, Okuda S, Kaira K, Oriuchi N, Nagamori S, and Kanai Y (2016b) Specific transport of 3-fluoro-l$\alpha$-methyl-tyrosine by LAT1 explains its specificity to malignant tumors in imaging. Cancer Sci 107:347-352.

Wiriyasermkul P, Nagamori S, Tominaga H, Oriuchi N, Kaira K, Nakao H, Kitashoji T, Ohgaki R, Tanaka H, Endou H, et al. (2012) Transport of 3-fluoro-L- $\alpha$-methyltyrosine by tumor-upregulated L-type amino acid transporter 1: a cause of the tumor uptake in PET. J Nucl Med 53:1253-1261.

Wongthai P, Hagiwara K, Miyoshi Y, Wiriyasermkul P, Wei L, Ohgaki R, Kato I, Hamase K, Nagamori S, and Kanai Y (2015) Boronophenylalanine, a boron delivery agent for boron neutron capture therapy, is transported by ATB ${ }^{0,+}$, LAT1 and LAT2. Cancer Sci 106:279-286.

Address correspondence to: Dr. Yoshikatsu Kanai, Department of Biosystem Pharmacology, Graduate School of Medicine, Osaka University, 2-2 Yamadaoka, Suita, Osaka 565-0871, Japan. E-mail: ykanai@pharma1.med.osaka-u.ac.jp 